\title{
Model studies of dense water overflows in the Faroese Channels
}

\author{
Alan Cuthbertson • Peter Davies • \\ Nataliya Stashchuk • Vasiliy Vlasenko
}

Received: 30 September 2013 / Accepted: 19 December 2013 / Published online: 22 January 2014

(C) Springer-Verlag Berlin Heidelberg 2014

\begin{abstract}
The overflow of dense water from the Nordic Seas through the Faroese Channel system was investigated through combined laboratory experiments and numerical simulations using the Massachusetts Institute of Technology General Circulation Model. In the experimental study, a scaled, topographic representation of the Faroe-Shetland Channel, Wyville-Thomson Basin and Ridge and Faroe Bank Channel seabed bathymetry was constructed and mounted in a rotating tank. A series of parametric experiments was conducted using dye-tracing and drogue-tracking techniques to investigate deep-water overflow pathways and circulation patterns within the modelled region. In addition, the structure of the outflowing dense bottom water was investigated through density profiling along three cross-channel transects located in the Wyville-Thomson Basin and the converging, up-sloping approach to the Faroe Bank Channel. Results from the dye-
\end{abstract}

Responsible Editor: Jarle Berntsen

This article is part of the Topical Collection on the 5th International Workshop on Modelling the Ocean (IWMO) in Bergen, Norway 17-20 June 2013

A. Cuthbertson $\cdot$ P. Davies

Department of Civil Engineering, University of Dundee,

Dundee DD1 4HN, UK

P. Davies

e-mail: p.a.davies@dundee.ac.uk

N. Stashchuk $\cdot$ V. Vlasenko

School of Marine Science and Engineering, University of Plymouth,

Drake Circus, Plymouth PL8 4AA, UK

N. Stashchuk

e-mail: nataliya.stashchuk@plymouth.ac.uk

V. Vlasenko

e-mail: vasyl.vlasenko@plymouth.ac.uk

Present Address:

A. Cuthbertson $(\square)$

Institute for Infrastructure and Environment, Heriot Watt University,

Edinburgh EH14 4AS, UK

e-mail: a.cuthbertson@hw.ac.uk tracing studies demonstrate a range of parametric conditions under which dense water overflow across the WyvilleThomson Ridge is shown to occur, as defined by the Burger number, a non-dimensional length ratio and a dimensionless dense water volume flux parameter specified at the FaroeShetland Channel inlet boundary. Drogue-tracking measurements reveal the complex nature of flow paths and circulations generated in the modelled topography, particularly the development of a large anti-cyclonic gyre in the Wyville-Thompson Basin and up-sloping approach to the Faroe Bank Channel, which diverts the dense water outflow from the Faroese shelf towards the Wyville-Thomson Ridge, potentially promoting dense water spillage across the ridge itself. The presence of this circulation is also indicated by associated undulations in density isopycnals across the Wyville-Thomson Basin. Numerical simulations of parametric test cases for the main outflow pathways and density structure in a similarly-scaled Faroese Channels model domain indicate excellent qualitative agreement with the experimental observations and measurements. In addition, the comparisons show that strong temporal variability in the predicted outflow pathways and circulations have a strong influence in regulating the Faroe Bank Channel and Wyville-Thomson Ridge overflows, as well as in determining the overall response in the Faroese Channels to changes in the Faroe-Shetland Channel inlet boundary conditions.

Keywords Faroese Channels · Dense water outflows · Circulations · Overflows · North Atlantic · Laboratory model · Computational model

\section{Introduction}

The south-westwards outflow of relatively cold and fresh water from the Nordic Seas to the North Atlantic Ocean is known to occur partly in the surface waters along the Greenland coast and partly at depth via several overflow locations along the Greenland-Scotland Ridge (GSR; see for 
example Hansen and Østerhus 2000; Olsen et al. 2008). In the eastern section of the GSR, between Iceland and Scotland, about $2.1 \mathrm{~Sv}$ (on average) of the overflow water entering the Wyville Thomson Basin (WTB) from the Faroe Shetland Channel (FSC) debouches into the North Atlantic via the Faroe Bank Channel (FBC). In addition, there are spatially and temporally intermittent flows of undiluted FSC bottom water of about $1 \mathrm{~Sv}$ over the Iceland-Faroe Ridge (IFR) and 0.2 to $0.3 \mathrm{~Sv}$ (Sherwin et al. 2008) over the Wyville Thomson Ridge (WTR; see Fig. 1a).

The latter component is the principal focus of attention here. Observational evidence (Sherwin and Turrell 2005; Johnson et al. 2010; Sherwin et al. 2008) indicates that the WTR overflow forms a large part of the waters occupying the upper part of the water column in the northern Rockall Trough, entering via the Ellett Gully (EG) between the Faroe Bank (FB) and the Ymir Ridge (YR) - see Fig. 1b. The spatial distribution of transport across the WTR itself is uncertain; the overflow has been assumed previously (Murray 1886; Saunders 1990) to cross at the lowest, central, part of the ridge, but Ellett (1998) and Sherwin and Turrell (2005) have noted that a large component appears to cross near the Faroe Bank before being channelled to the EG (Fig. 1b).

Many uncertainties remain over the processes responsible for the leakage of flow over the WTR and the pathways taken by the overflow as it crosses the WTR and finds its way to the Rockall Trough. For example, the degree to which the barrier presented by the Faroe Bank itself and the topographic constriction at the FBC imposes retroflection and recirculation of the dense overflow water upstream of the sill remains unclear.
Similarly, the roles played by hydraulic and topographical controls at the sill itself (Whitehead 1998; Borenäs and Lundberg 2004; Girton et al. 2006) in limiting the volume flux carried downstream (and thereby diverting excess FBC overflow waters across the WTR) require further attention. Finally, open questions remain on the importance of exceedance of the transport capacity (Wåhlin 2002) of the FBC, coupled with topographically induced departures from geostrophy in the FBC deep water overflow (Davies et al. 2006), in regulating and limiting the discharge over the sill and promoting spillage over the WTR.

To investigate such processes, a combined laboratory and numerical modelling study has been undertaken of the deepwater circulation and outflow characteristics in the Faroese Channels, focused on defining the parametric conditions that result in WTR spillage. In this regard, previous field studies of the FBC deep-water outflow (e.g. Lake et al. 2005; Johnson and Sanford 1992) have indicated the presence of comparatively homogeneous (i.e. roughly constant temperature) deepand surface water masses, separated by a permanent and welldefined pycnocline. Lake et al. (2005) and others (e.g. Borenäs and Lundberg 2004) have thus suggested that the FBC deep-water outflow can be approximated by adopting a $1 \frac{1}{2}$ layer hydraulic modelling approach, whereby the deep and dynamically inactive upper layer is assumed to have little effect on the characteristics of the deep water outflow. In other words, the surface currents generated by the inflow of warm North Atlantic waters to the Nordic Seas are assumed to penetrate insufficiently deep to affect the deep bottom-water circulation and outflow in the FBC.

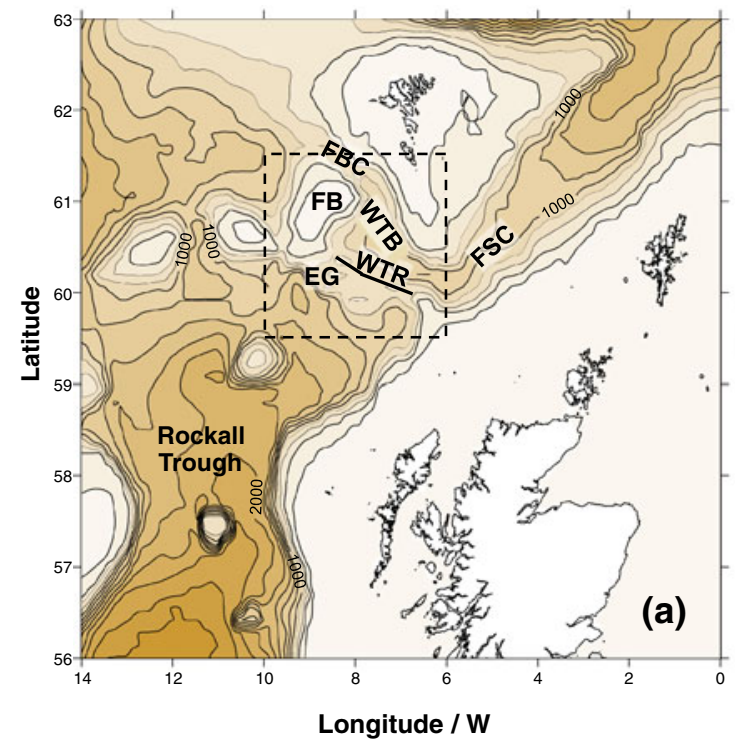

Fig. 1 Overview maps showing main seabed topographic features of the Faroese Channels, including FSCFaroe-Shetland Channel, WTB WyvilleThomson Basin, WTR Wyville-Thomson Ridge, $F B$ Faroe Bank, FBC Faroe Bank Channel, EG Ellet Gully, YRYmir Ridge, $C D$ Cirolana Deep,

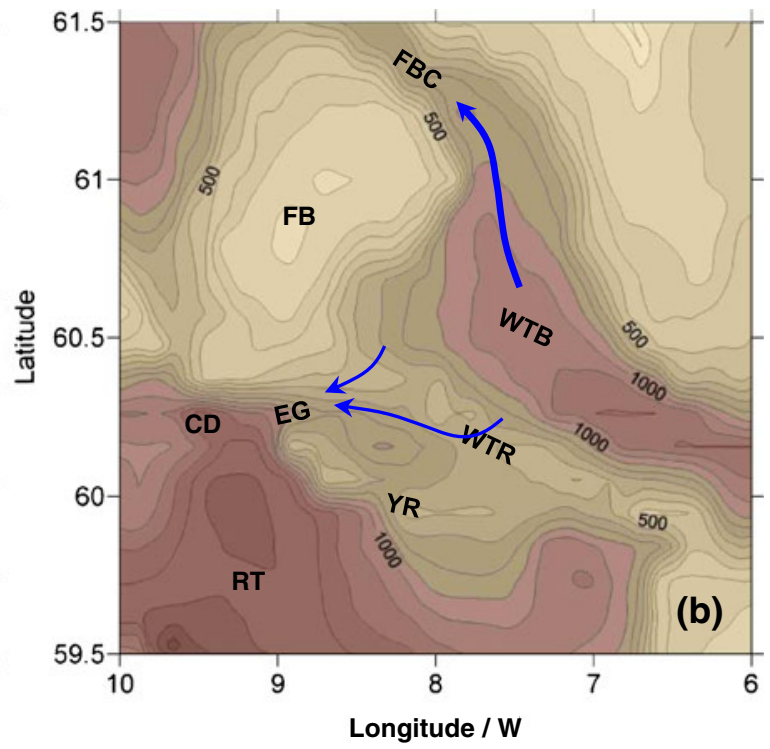

$R T$ Rockall Trough. Detailed seabed topography enclosed by dashed rectangle in a shown in $\mathbf{b}$, along with the main Norwegian Sea Deep Water (NSDW) outflow pathways (blue arrows) through the FBC and across the WTR 
This assumption has been adopted in both the laboratory and numerical studies presented herein and, thus, the potential influence of surface currents is not considered in this current study.

\section{The physical system}

\subsection{Topographic model of region}

The detailed seabed topography for the Faroese Channels was extracted from a bathymetric dataset provided by the General Bathymetric Chart of the Oceans (GEBCO, one arc-minute grid resolution). The main region of interest for the present study considers the dense water inflow from the Norwegian Sea (Norwegian Sea Deep Water, NSDW) at the lower end of the FSC, its expansion and topographic routing within the WTB and the resulting outflow pathways either (1) wholly through the up-sloping, converging approach to the FBC threshold sill or (2) partly across the WTR and through the EG in addition to the FBC (see Fig. 1). The topographic data for this region were transformed from the standard geographic coordinate system into a reoriented local Cartesian coordinate system $(X, Y$, and $Z$ ). This was then rescaled in the horizontal $(X$ and $Y)$ and vertical $(Z)$ directions by scale factors of 1:100,000 and $1: 3,000$, respectively, resulting in a vertical distortion in the seabed topography model of $\sim 30$ (see Fig. 2). This distorted model approach is in general accordance with previous experimental studies of outflows in the Faroe Bank Channel region (e.g. Davies et al. 2006; Cuthbertson et al. 2011).

\subsection{Physical system}

The initial, undisturbed experimental configuration is one in which the installed seabed topography is submerged within a large rectangular tank filled with a homogeneous ambient fluid of depth $H$ and density $\rho_{0}$ which is in a state of solid body rotation about the vertical $Z$-axis, with angular velocity $\Omega=(0,0, \Omega)$. At time $t=0$, a dense water inflow of source and excess density $\rho_{1}$ and $(\Delta \rho)_{0}$, respectively $\left[\rho_{1}=\rho_{0}+(\Delta \rho)_{0}\right]$, dynamic viscosity $\mu$ and initial volume flux $Q_{1}$ is introduced at the upstream end of the topographic model [FSC boundary inlet; Figs. 2 and 3b] via a near-bed radial source manifold. From this inlet condition, defined by typical vertical $h_{1}$ and horizontal $l_{1}$, inlet flow dimensions at the entry section (see insert, Fig. 3b), the dense bottom-water inflow is topographically steered through the model bathymetry before spilling over a threshold sill (i.e. at the FBC boundary outlet; Fig. 2) and, under specific parametric conditions (see below), through the gap in the modelled Wyville-Thomson Ridge [WTR spill, Fig. 3b] and out through the EG outlet (Fig. 2).
Fig. 2 Transformed and scaled seabed topography used in the laboratory model set-up, with model inlet and outlet boundary locations highlighted. Colour bar scale indicates the height (in centimeters) above the lowest bed elevation $\left(z_{b, \min }=0\right)$ in the topographic model. Microconductivity probe measurement transects S1-S3 shown along with MITgcm WTB transect (dotted white line) also shown. Abbreviations for prominent seabed features as detailed in Fig. 1 caption

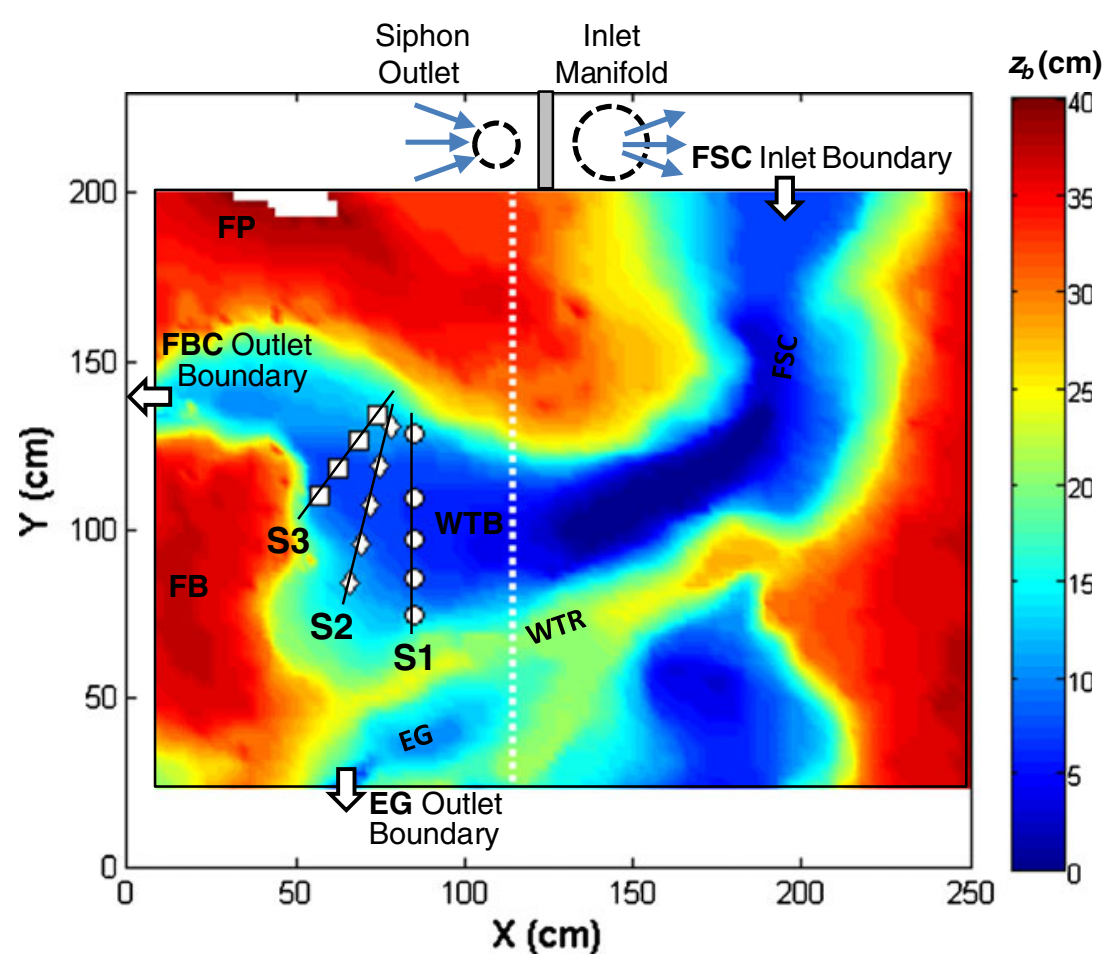




\section{Experiment arrangement}

\subsection{Set up and procedure}

The experimental study was conducted in a transparent-walled rectangular tank, fabricated from acrylic material with overall dimensions of $2.5 \mathrm{~m}$ long $\times 2.2 \mathrm{~m}$ wide $\times 0.4 \mathrm{~m}$ deep, mounted on a rotating table. The scaled topographic model was constructed by defining the full scale bathymetric data at a contour level resolution $\Delta z=30 \mathrm{~m}$. This allowed the contoured seabed topography to be represented in the model at the appropriate vertical scale $(1: 3,000)$ by layering pre-cut $10 \mathrm{~mm}$ sheets of appropriate shape. The resulting stepped-contour topographic model of the region (see Fig. 3a) was installed within the rotating tank, with a waterproof grout applied to smooth out the steps between contour layers. The topographic model was then smoothed further and painted matt black to minimise reflections and maximise contrast for dye and drogue-tracking experimental measurements (see Fig. 3b).

The scaled model bathymetry was installed within the tank with the minimum in-channel bed elevation $z_{b, \min }=0$ located in the centre of the WTB (as shown in Fig. 2), corresponding to the oceanic water depth $H \approx 1,200 \mathrm{~m}$ at this location. Similarly, the scaled minimum bed elevations $z_{b, \min }$ at the FSC inlet section, the FBC outlet section and at the depression in the WTR were modelled as $z_{b, \min }=70,130$ and $200 \mathrm{~mm}$, respectively [corresponding to oceanic water depths $H=990$, 810 and $600 \mathrm{~m}$, respectively]. As the minimum bed elevation at the FBC outlet is higher than at the FSC inlet, the dense water overflow across the FBC sill is expected to be hydraulically controlled near this location (Girton et al. 2006). As a consequence, the restricting effects of this hydraulic control are expected to limit the transport capacity through the FBC (Wåhlin 2002; Davies et al. 2006), in turn influencing the behaviour of the subcritical dense water outflow layer within the WTB and FSC.

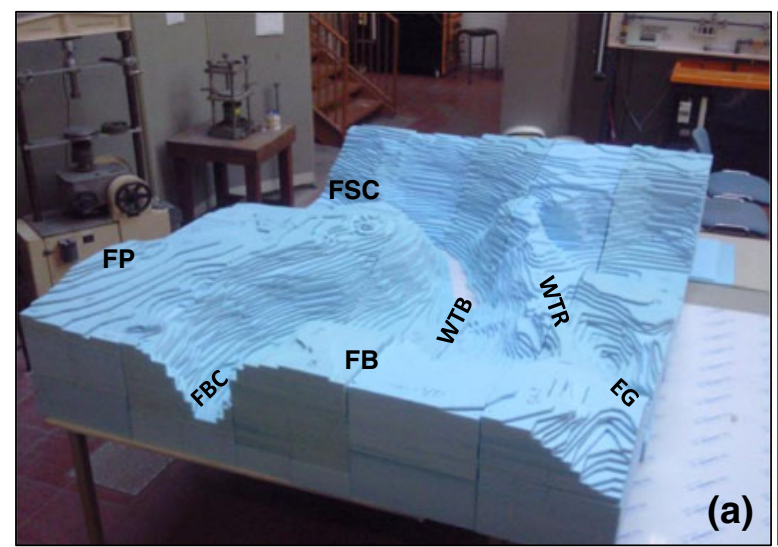

Fig. 3 a Contour-layered construction of topographic model of Faroese Channels showing abbreviations for prominent seabed features (as detailed in Fig. 1 caption); b photograph showing dye-tracing experimental set-up,
Prior to each experimental run, the rectangular tank was filled with freshwater $\left(\rho_{0}=998 \mathrm{~kg} \mathrm{~m}^{-3}\right)$ to a total in-channel depth of $H=0.372 \mathrm{~m}$, largely submerging the modelled seabed bathymetry. The fluid was then spun-up from rest by rotating the turntable at a prescribed constant angular velocity $\Omega$ for several hours to ensure that solid body rotation had been attained (van Heijst et al. 1990). Two angular velocities $\Omega=$ 0.185 and $0.25 \mathrm{~s}^{-1}$ were used in the present study [corresponding to Coriolis parameter values of $f(=2 \Omega)=0.37$ and $0.50 \mathrm{~s}^{-1}$, respectively]. At the start of each run, brine solution of constant density $\rho_{1}\left(\rho_{1}=1,005,1,011\right.$ and $\left.1,020 \mathrm{~kg} \mathrm{~m}^{-3}\right)$ was pumped into a small basin immediately upstream of the FSC inlet section via a radial inlet diffuser manifold (Figs. 2 and 3). This feature was designed specifically to distribute the inflow uniformly across the FSC inlet section and minimise initial mixing between the dense and ambient fluids. The reduced gravitational acceleration $g^{\prime}\left[=g\left(\rho_{1}-\rho_{0}\right) / \rho_{0}=g(\Delta \rho)_{0} / \rho_{0}\right]$ values associated with the brine inflow conditions ranged from 0.068 to $0.212 \mathrm{~m} \mathrm{~s}^{-2}$ ( $g$ being the gravitational acceleration = $9.81 \mathrm{~m} \mathrm{~s}^{-2}$ ).

Once the interface elevation of the dense bottom-water layer exceeded the minimum bed elevation at the FSC inlet, a dense, bottom gravity current of brine was initiated that propagated along the descending bed topography from the FSC to the lowest point in the WTB. The thickness of the dense bottom layer gradually increased in the WTB, with the layer eventually spilling out over the FBC sill, a time after which quasi-steady outflow conditions were attained (at the initial inflow volume flux $\left.Q_{1}=0.167 \mathrm{ls}^{-1}\right)$. The inlet volume flux was then subsequently increased incrementally $\left(Q_{1}=0.167 \rightarrow 0.25 \rightarrow 0.333 \rightarrow\right.$ $0.433 \mathrm{ls}^{-1}$ ) at prescribed elapsed times during each experimental run, with the dense water outflow allowed to adjust to quasisteady conditions at each $Q_{1}$ value. Parametric changes between runs were thus introduced by varying (1) the source volume flux $Q_{1}$ of dense bottom water, (2) the density difference $(\Delta \rho)_{0}=\left(\rho_{1}-\rho_{0}\right)$ between the dense brine and ambient

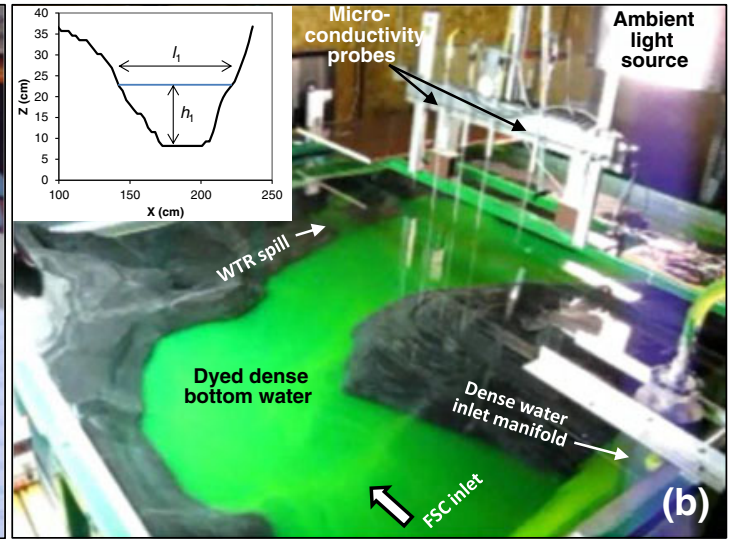

where fluorescene-dyed dense bottom water flowing through the smoothed topography is illuminated by an ambient light source. (Insert defines bottomwater layer thickness $h_{1}$ and interface width $l_{1}$ at FSC inlet boundary) 
receiving waters and (3) the Coriolis parameter $f(=2 \Omega)$. For all parametric conditions tested, the outflowing dense bottom layer either remained completely contained within the WTB, before spilling out freely through the FBC outlet section, or initiated a secondary outflow pathway across the WTR before passing out through the EG outlet (see Fig. 2). In both cases, the dense water overflow from the FBC and EG outlets was routed within the surrounding rectangular tank to a gravity-driven siphon arrangement at the tank outlet (Fig. 2), from where it was removed. Details of the full range of experimental conditions considered within the study are detailed in Table 1.

\subsection{Measurement techniques}

Two Jai CV-M4+CL, progressive scan, monochrome, digital CCD cameras were mounted directly above the rotating tank to record dense water outflow pathways and circulation patterns in the scaled topographic model, using dye-tracing and drogue-tracking techniques, respectively. For the dye-tracing runs, fluorescene was added directly to the dense source water sump prior to its supply at the FSC inlet section via the radial manifold feed. For the drogue-tracking experiments, $5 \mathrm{~mm}$ diameter, cylindrical-shaped drogue particles were deployed immediately downstream of the FSC inlet section. With quasisteady outflow conditions established, drogues of the appropriate density for the specified parametric conditions $\left(\rho=1,005 \rightarrow 1,020 \mathrm{~kg} / \mathrm{m}^{3}\right)$ were deployed at 30 -s intervals within the dense bottom inflow layer and were subsequently tracked in their passage through the topographic system. Spatial overlap between the two CCD camera view fields ensured that the individual drogue tracks could be accurately tracked and correlated between the two image fields. For both the dye and drogue tests, background illumination was provided by an ambient fluorescent light source. Images were captured at 24 frames per second and at a maximum resolution of $1,372 \times 1,024$ pixels using the Digiflow (Dalziel 2008) software package.

The spatial and temporal development of the density field $\rho(x, y, z, t)$ associated with the developing bottom outflow layer was also monitored by a fixed array of high-resolution microconductivity probes located along three cross-channel transects (S1-S3; Fig. 2) within the WTB and the converging, upsloping FBC approach channel. The probes were mounted on a rigid support frame, with a motorised rack system that allowed automated simultaneous and rapid profiling of the density fields along these three transects (see Davies et al. 2006; Cuthbertson et al. 2011) throughout the duration of the experiment. This procedure allowed cross-channel variations in isopycnal elevations to be identified and measured at the three transects, under different parametric conditions and at different elapsed times after the initiation of the flow.

\section{Scaling considerations}

\subsection{Dimensional analysis}

As the minimum bed elevation at the FSC inlet section was significantly lower than at the FBC outlet section, the inlet flow dimensions $\left(l_{1}, h_{1}\right)$ of the dense bottom-water layer were influenced by the hydraulically controlled outflow conditions at the FBC outlet section. In practice, this meant that these inlet flow dimensions could not be specified directly as independent parameters, their magnitude depending on the other externally varied source parameters $\left(Q_{1}, g^{\prime}\right.$ and $\left.f\right)$. To resolve this problem and to determine the likely dependence of $l_{1}$ and $h_{1}$ on the other external parameters, dimensional analysis was undertaken using the following functional relationship:

$h_{1}, l_{1}=\phi\left(Q_{1}, g^{\prime}, f\right)$

[Note that fluid viscosity $\mu$ is not included in the dimensional analysis; Reynolds numbers of the laboratory flows are assumed to be sufficiently high (see below) that viscous effects can be neglected.] Applying dimensional analysis to Eq. (1) leads to the following non-dimensional functional relationship:

$\left(\frac{h_{1} f^{2}}{g^{\prime}}, \frac{l_{1} f^{2}}{g^{\prime}}\right)=\phi\left(\frac{Q_{1} f^{5}}{g^{\prime 3}}\right)$

The behaviour of the dense bottom-water outflow through the model topography can, thus, be conveniently described in terms of the non-dimensional inlet flow dimensions $h_{1} f^{2} / g^{\prime}$ and $l_{1} f^{2} / g^{\prime}$ and a non-dimensional transport parameter $Q_{1}^{*}=$ $Q_{1} f^{5} / g^{\prime}{ }^{3}$. In addition, the well-established non-dimensional dynamical parameters describing buoyancy-driven flows in rotating systems can also be used, viz.

$$
\begin{aligned}
& F_{1}=v_{1} /\left(g^{\prime} h_{1}\right)^{1 / 2} \text { the densimetric Froude number, } \\
& \mathrm{Ro}_{1}=v_{1} /\left(l_{1} f\right) \quad \text { the Rossby number, and }
\end{aligned}
$$

$\operatorname{Re}_{1}=4 \rho_{1} v_{1} h_{1} / \mu \quad$ the Reynolds number,

where $v_{1}=Q_{1} / A_{1}$ is the mean inlet velocity $\left(A_{1}\right.$ being the upstream deep-water flow area defined from the FSC inlet section shape and dimensions $h_{1}$ and $l_{1}$, see below). Note that other typical dimensionless quantities such as the Burger number $\mathrm{Bu}_{1}\left[=\mathrm{Ro}_{1}^{2} F_{1}^{-2}=g^{\prime} h_{1} /\left(l_{1}^{2} f^{2}\right)\right]$ and the Ekman number $\mathrm{Ek}\left[=\left(l_{1} / h_{1}\right) \operatorname{Ro}_{1} \operatorname{Re}_{1}^{-1}=\mu /\left(\rho_{1} f h_{1}^{2}\right)\right]$ are not independent dynamical parameters as they are derived directly from $R e_{1}, F_{1}$ and $R o_{1}$ and the inlet length scale ratio $l_{1} / h_{1}$, as shown 


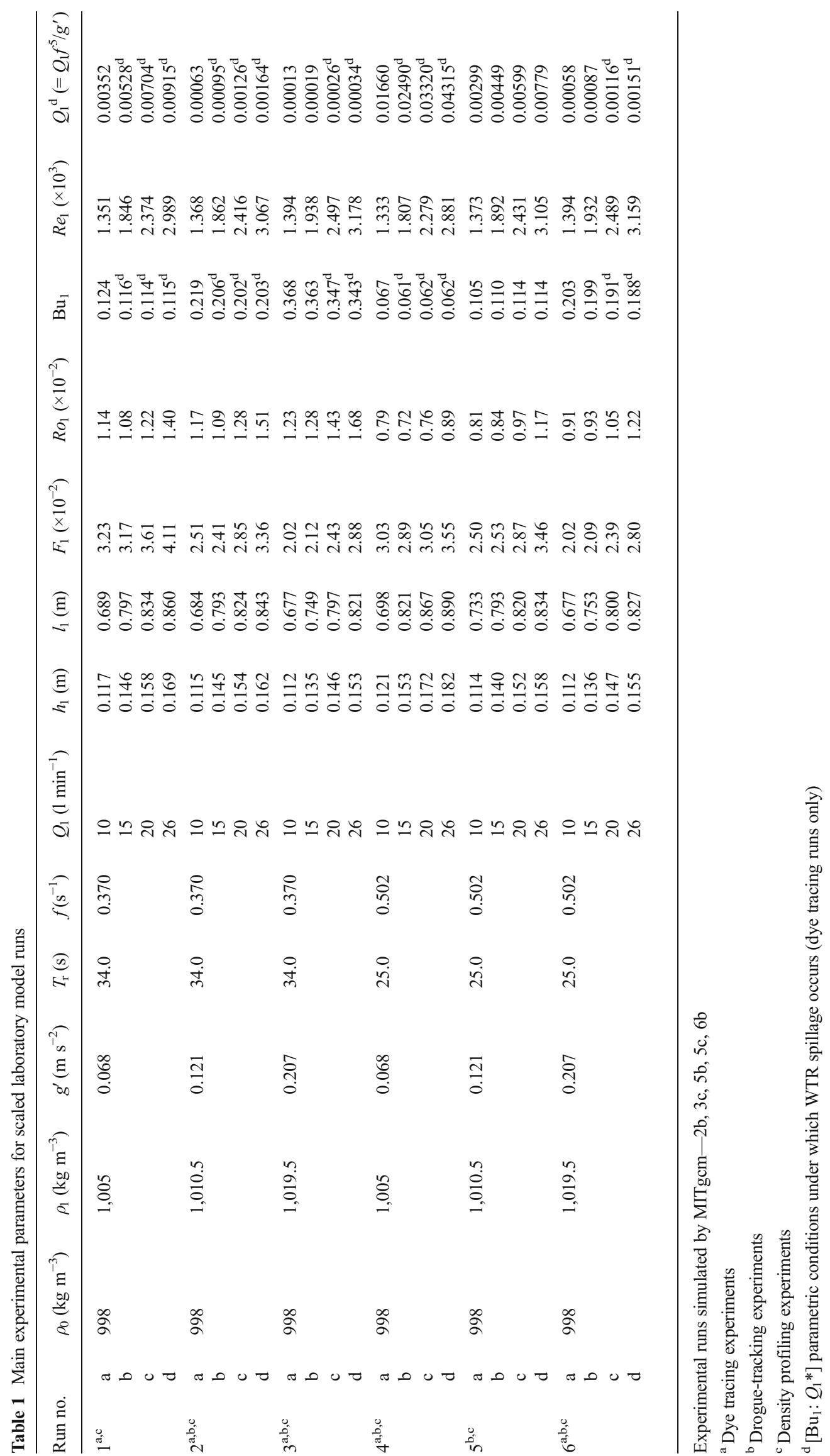


(Davies et al. 2006). Similarly, the non-dimensional inlet dimensions and transport parameter, derived previously from dimensional analysis, can also be re-written as follows:

$$
\frac{h_{1} f^{2}}{g^{\prime}}=\left(\frac{h_{1}}{l_{1}}\right)^{2} \mathrm{Bu}_{1}^{-1}
$$

$$
\frac{l_{1} f^{2}}{g^{\prime}}=\left(\frac{h_{1}}{l_{1}}\right) \mathrm{Bu}_{1}^{-1}
$$

$Q_{1}^{*}=\frac{Q_{1} f^{5}}{g^{\prime 3}}=\frac{1}{\xi}\left(\frac{h_{1}}{l_{1}}\right)^{4} \mathrm{Bu}_{1}^{-3} \mathrm{Ro}_{1}$

where $\xi\left(=l_{1} h_{1} / A_{1}\right)$ is a channel cross-section shape factor (Laanearu and Davies 2007). For the range of $h_{1}$ values attained during the experiments (see Table 1), the shape factor $\xi$ at the FSC inlet section varied between 1.38 and 1.47. [Note that, by definition, the same relationship between shape factor $\xi$ and $h_{1}$ should also apply at the field-scale inlet section within the FSC]. For the range of parametric conditions tested, the dynamic non-dimensional parameters $\mathrm{Fr}_{1}, \mathrm{Ro}_{1}$ and $\mathrm{Bu}_{1}$ were in the range $O\left(10^{-2}\right), O\left(10^{-2}-10^{-3}\right)$ and $O\left(10^{-1}-10^{-2}\right)$, respectively, and are, thus, of the same order as values predicted for FSC and WTB field scale conditions (Girton et al. 2006; Mauritzen et al. 2005). By contrast, corresponding values of the inlet Reynolds number $R e_{1}$ were $O\left(10^{3}\right)$ in the scaled model and significantly lower than the oceanic bottom outflow conditions within the FSC. However, these model $R e_{1}$ values are deemed sufficiently high to assume that the dependence of outflow properties on $R e_{1}$ can be neglected.

\subsection{FSC boundary conditions}

As the deep-water oceanic overflow conditions within the FSC are geostrophically adjusted (Borenäs and Lundberg 2004), it is important that geostrophic adjustment of the dense bottom-water inflow within the scaled topographic model also occurs as close to the FSC inlet section as possible. This adjustment can be estimated to occur within one internal Rossby radius $\left[=\left(g^{\prime} h_{1} / f\right)^{1 / 2}\right]$ of the FSC inlet section (Laanearu and Lundberg 2003), a distance which is less than $0.3 \mathrm{~m}$ for the full parametric range considered (Table 1). The geostrophic adjustment of the dense bottom-water inflow is, therefore, always expected to occur in the FSC region of the topographic model (Fig. 2).

\section{Experimental results}

\subsection{Dye tracing observations}

Figure 4 shows typical plan form images of typical dense water outflow pathways obtained during the dye-tracing runs with different Burger number $\mathrm{Bu}_{1}$ and non-dimensional transport $Q_{1}^{*}$ conditions specified at the FSC inlet section. Note that the colour variation shown in these traces reflects nonuniformity in the illumination of the fluorescene-dyed dense bottom water by the ambient light sources. These dye-tracing tests were thus primarily conducted to illustrate range of flow conditions under which spillage across the WTR occurs. In this regard, it is apparent that for a certain parametric range of $\mathrm{Bu}_{1}: Q_{1}^{*}$ conditions, no spillage is observed across the WTR (e.g. Fig. 4a), whilst other parametric conditions result in strong dense water overflows across the WTR (Fig. 4c, d). However, when comparing the different experimental runs in which WTR spillage occurs (see the $\mathrm{Bu}_{1}: Q_{1}^{*}$ values marked asterisk in Table 1), the parametric dependences are not immediately obvious. It is shown that, for individual runs with fixed values of $g^{\prime}$ and $f$, the propensity for WTR spillage and, indeed, the magnitude of the dense water overflow generated across the WTR, increases as the dense water transport rate $Q_{1}$ increases (see Table 1).

A non-dimensional parametric classification of the tendency for WTR overflows to occur is presented in terms of the $\mathrm{Bu}_{1}$ and $Q_{1}^{*}$ values in Fig. 5a. The plot appears to indicate delineation between the parametric range under which WTR spill occurs (blue crosses, Fig. 5a) and conditions under which no spill is observed (red circles, Fig. 5a). In addition, it is apparent from Fig. 5a that, at lower values of $\mathrm{Bu}_{1}$, the relative increase in the importance of rotation to stratification effects means that the conditions required for WTR spillage tend to occur at higher non-dimensional transport rates $Q_{1}^{*}$. It is also interesting to note the apparent shift (increase) in the $\mathrm{Bu}_{1}$ values for the no WTR spill runs, compared with the WTR spill conditions (for otherwise fixed $g^{\prime}$ and $f$ values). This is due to the variation in the cross-sectional dimensions $\left(h_{1}, l_{1}\right)$ under different volumetric influxes $Q_{1}$ specified at the FSC inlet. With the inlet Burger number $\mathrm{Bu}_{1}=g^{\prime} h_{1} /\left(l_{1}^{2} f^{2}\right)$, the dimensional ratio $h_{1} / l_{1}^{2}$ (and hence non-dimensional length ratio $h_{1} / l_{1}$ ) clearly controls the magnitude of $\mathrm{Bu}_{1}$ in any given experimental run (i.e. for fixed $g^{\prime}$ and $f$ ). It should be noted that the "non-uniformity" of the FSC inlet cross-sectional shape (i.e. non-constant shape parameter $\xi$ value) means that the observed variation in $\mathrm{Bu}_{1}$ as a function of ratio $h_{1} / l_{1}^{2}$ is not straightforward. Specifically, the ratio $h_{1} / l_{1}^{2}$ initially increases then decreases with an increasing magnitude of $Q_{1}$ (and hence $h_{1}$ ). By comparison, for more "uniform" triangular or parabolic cross-sections, this ratio $h_{1} / l_{1}^{2}$ will always reduce as $h_{1}$ increases, although the rate of this reduction will also diminish with increasing depth $h_{1}$. 


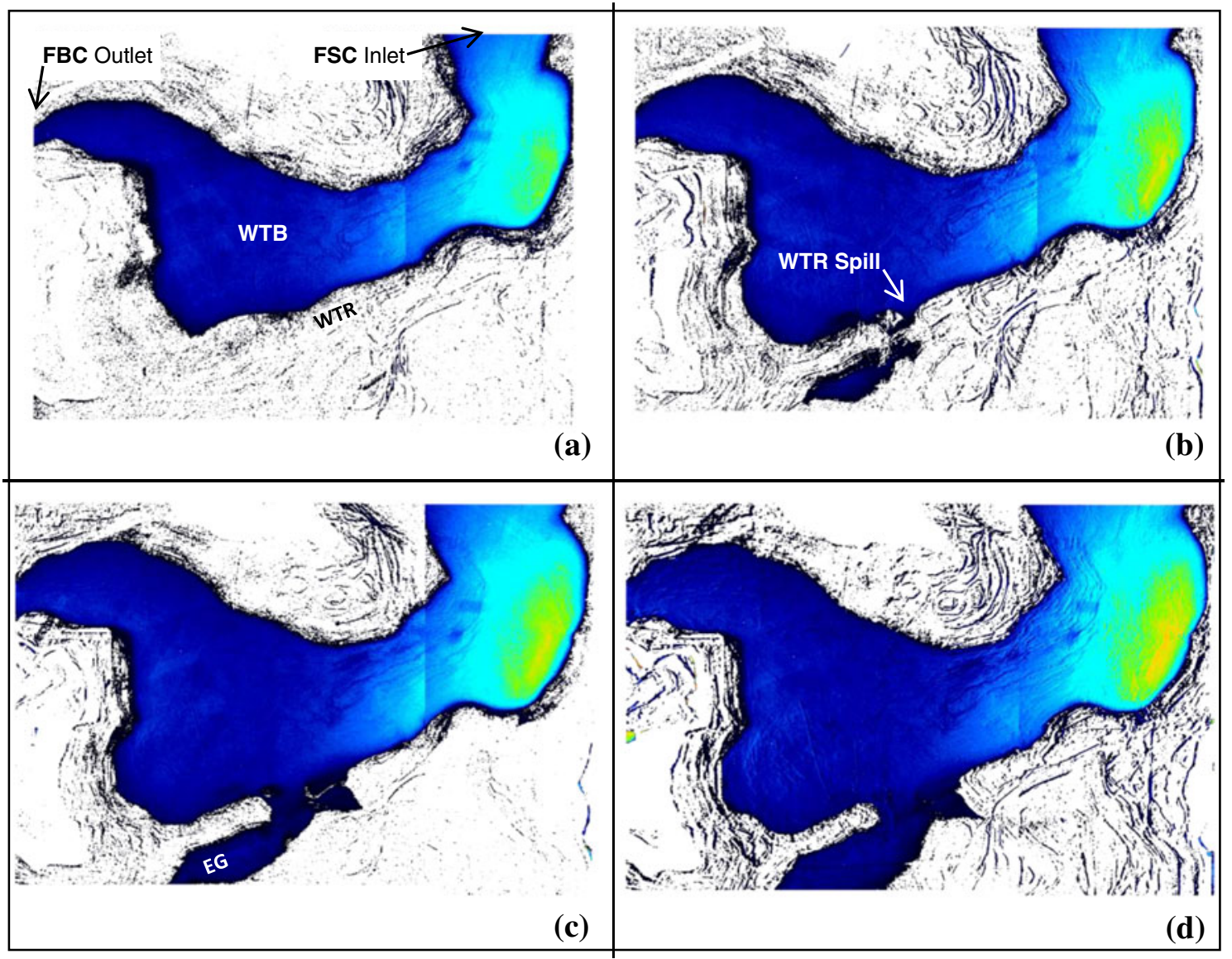

Fig. 4 Dense bottom-water overflow pathways observed through illuminated fluorescene dye-tracing for run 1 conditions (see Table 1 ) with $\mathrm{Bu}_{1}$ : $Q_{1}^{*}$ values of a 0.124:0.00352 (no WTR spill), b 0.116:0.00528 (WTR spill), c 0.114:0.00704 (WTR spill) and d 0.115:0.00915 (WTR spill)

The marked parametric delineation between WTR spill and no-spill conditions is shown more clearly by plotting a regime diagram of $Q_{1}^{*}$ versus the non-dimensional inlet length ratio $h_{1} / l_{1}$ (see Fig. 5b). Within this figure, the vertical dashed line drawn at $h_{1} / l_{1}=0.181$, separating the WTR spill and no-spill conditions, clearly represents only a first approximation of this

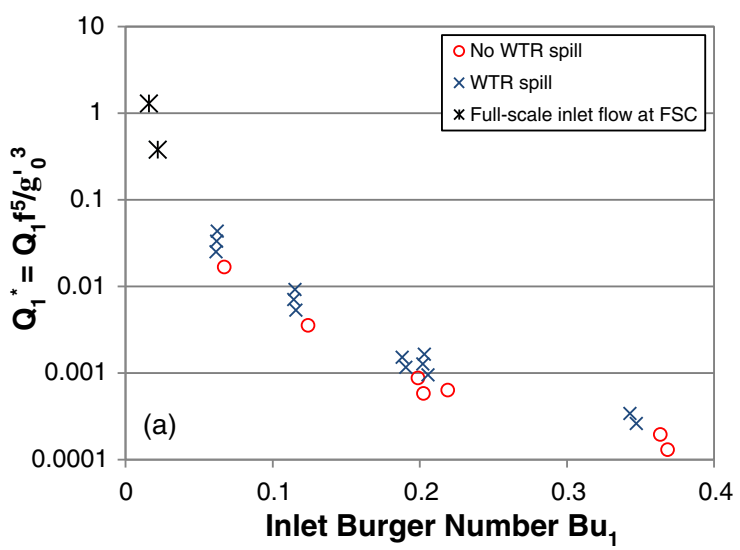

Fig. 5 a Relationship between non-dimensional transport parameter $Q_{1}^{*}$ and the inlet Burger number $B u_{1}$ showing parametric conditions under which WTR spill and no spill occur, $\mathbf{b}$ regime diagram of $Q_{1}^{*}$ versus nondimensional inlet length ratio $h_{1} / l_{1}$ indicting delineation between spill and delineation, which, based on the available experimental data, is valid only up to $Q_{1}^{*}=0.5$. Given the topographic configuration of the laboratory model, within which the minimum bed elevations at the FBC sill and WTR outlets are significantly higher than that at the FSC inlet section, it is perhaps unsurprising that such a delineation can be defined simply on the

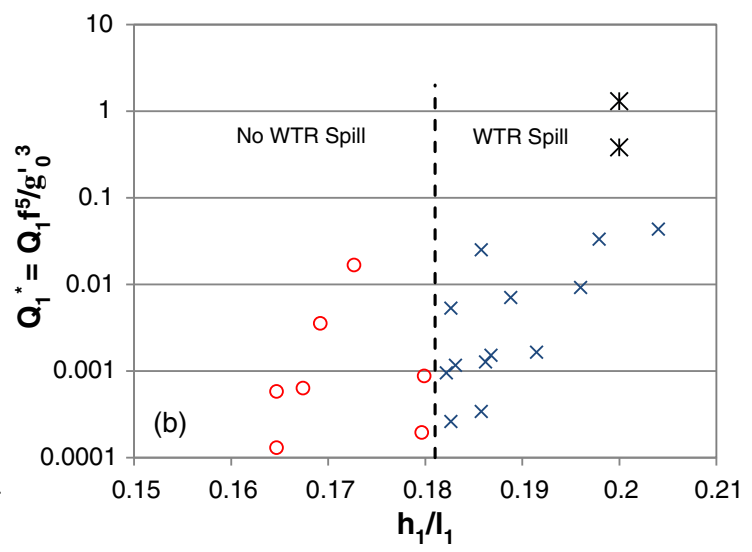

no-spill conditions. Typical adjusted estimates of $Q_{1}^{*}, \mathrm{Bu}_{1}$ and $h_{1} / l_{1}$ values for the full-scale, deep-water inflow conditions in the FSC are shown for comparison 
inlet length ratio $h_{1} / l_{1}$, as this is undoubtedly, to some extent at least, controlled by the FBC/WTR outflow conditions themselves.

Comparison between the laboratory-scale parametric conditions and full-scale conditions experienced in the FSC is also be considered within Fig. 5. For previous field surveys, it has been noted that typical oceanic values for the deep-water overflow at the FSC inlet section are $Q_{1}=2.0-2.5 \mathrm{~Sv}$ $\left(10^{6} \mathrm{~m}^{3} \mathrm{~s}^{-1}\right), g^{\prime}=0.0043-0.006 \mathrm{~m} \mathrm{~s}^{-2}, f=1.27 \times 10^{-4} \mathrm{~s}^{-1}$; $l_{1}=100 \mathrm{~km}$ and $h_{1}=600 \mathrm{~m}$ (Borenäs and Lundberg 2004; Mauritzen et al. 2005). The non-dimensional transport parameter $Q_{1}^{*}$ can thus be found to range from $3.05 \times 10^{-7}$ to $1.04 \times$ $10^{-6}$, with corresponding inlet Burger numbers and nondimensional length ratios ranging from $\mathrm{Bu}_{1}=0.022-0.016$ and $h_{1} / l_{1}=0.006$, respectively. Within the scaled, laboratory model, the corresponding magnitudes of $Q_{1}^{*}, \mathrm{Bu}_{1}$ and $h_{1} / l_{1}$ are $O\left(10^{-2}-10^{-4}\right), O\left(10^{-2}-10^{-1}\right)$ and $O\left(10^{-1}\right)$, respectively (see Table 1 and Fig. 5). Whilst the $\mathrm{Bu}_{1}$ values correspond in magnitude at both scales (as anticipated), discrepancies exist between the field and model scale $Q_{1}^{*}$ and $h_{1} / l_{1}$ values, which arise from the vertical distortion imposed in the laboratory model. For the non-dimensional length ratio $h_{1} / l_{1}$, this is easily rectified by multiplying the field-scale $h_{1} / l_{1}$ value by the ratio of horizontal and vertical scaling factors (i.e. $10^{5} / 3,000=$ 33.3), hence yielding the adjusted field-scale length ratio $h_{1} / l_{1}$ $=0.2$. For the non-dimensional flux parameter $Q_{1}^{*}$, the scaling discrepancy arises from the $\left(h_{1} / l_{1}\right)^{4}$ term in Eq. 8, which, at field and model scales, equates to $\left(600 / 10^{5}\right)^{4}=1.296 \times 10^{-9}$ and $(0.2 / 1.0)^{4}=1.60 \times 10^{-3}$, respectively. Thus, matching the magnitudes $Q_{1}^{*}\left(l_{1} / h_{1}\right)^{4}$ at both model and field scales, a vertically distorted, non-dimensional transport $Q_{1}^{*}$ can be obtained from the actual FSC inlet conditions, allowing direct comparison with model-scale parametric conditions in Fig. 5. These adjusted field-scale transport parameters are estimated from $Q_{1}^{*}(0.2 / 1.0)^{4} /\left(600 / 10^{5}\right)^{4}$ to range between 0.377 and 1.284 for the corresponding $\mathrm{Bu}_{1}$ values of 0.022 and 0.016 (see Fig. 5a). Whilst these adjusted $Q_{1}{ }^{*}$ values are an order of magnitude higher than the parametric conditions tested in the laboratory model, they accord well with the general trend shown by the laboratory-scale parametric conditions. Furthermore, plotting the adjusted field-scale $Q_{1}^{*}$ values against the vertically distorted, inlet length ratio $h_{1} / l_{1}(=0.2$; see Fig. $5 b)$, it is clear from these parametric considerations that such oceanic values of the NSDW inflow measured at the FSC inlet would be expected to result in spillage across the WTR.

\subsection{Drogue-tracking observations}

Drogue-tracking runs were conducted in steady-state, densewater outflows, as defined by specific $Q_{1}^{*}$ : $\mathrm{Bu}_{1}$ parametric conditions at the upstream FSC boundary (see Table 1). These steady-state conditions allowed neutrally buoyant drogues to be added at $30 \mathrm{~s}$ intervals to the dense bottom- water layer immediately downstream of the FSC inlet section. This procedure ensured that each individual drogue could be tracked easily during its passage through the topographic system. Figure 6 shows a number of drogue-tracking outputs, both for an experiment run under which no WTR spill occurred (e.g. Fig. 6a, b) and corresponding runs in which WTR spill did occur (e.g. Fig. 6c-f). The time interval between individual drogue positions shown in the plots is $\Delta t=0.42 \mathrm{~s}$ (i.e. equivalent to every 10th image frame at $24 \mathrm{fps}$ ). (Note: a corresponding velocity scale cannot be determined as the vertical position of the individual drogues in the lower dense water layer is uncertain).

Immediately downstream from the FSC inlet, the majority of released drogues follow similar paths along the Faroese shelf edge, with a few also showing the influence of smallscale vorticity in the dense outflow layer towards the bottom of the FSC (Fig. 6a, c, 2d). Subsequently, in the vicinity of the $90^{\circ}$ turn in channel orientation (to the right) and channel constriction at the transition between the FSC and WTB, a large proportion of the drogues follow paths on the right hand side of the outflow layer (looking downstream), as would be expected for geostrophically adjusted dense water outflow conditions. It is noted, however, that some drogue paths are influenced by eddies forming on the left side of the channel immediately prior to this constriction (see Fig. $6 \mathrm{~b}, \mathrm{f}-\mathrm{h}$ ). Once past the constriction, many of the drogue tracks tend to deviate (to a lesser or greater degree) away from the right hand side of the outflow, with many paths deflected significantly to the left in the widening WTB section. These diversions result in a number of drogues following outflow pathways to the FBC along the left side of the WTB (i.e. adjacent to the WTR) and in the converging, up-sloping approach to the FBC outlet, whilst others are shown to be transported across the WTR in the dense water overflow (Fig. 6c, d). It is unclear whether these deflected drogue paths represent a persistent characteristic of the dense water outflow structure (i.e. general anticyclonic circulation) within the WTB/FBC approach for all parametric conditions tested. (Note: Fig. 6e shows little evidence of these deflected pathways, with the outflowing drogues remaining on the Faroe Plateau (FP) side of the channel). Analysis of further drogue tracks in the WTB/FBC approach channel (Fig. 7) also reveals the presence of strongly deflected drogue paths in this region. One drogue, in particular (see Fig. 7b), is shown to become trapped in an anti-cyclonic eddy at the entrance to FBC approach channel. The evidence presented from these drogue tracks appears to indicate the presence of large-scale, anti-cyclonic eddy or closed circulation (gyre) in the WTB/FBC approach channel, at least on an intermittent basis. This feature is shown to affect significantly the deep-water flow paths within the WTB by deflecting the dense water overflow layer southwards towards the WTR and potentially promoting spillage across the WTR. A schematic representation of the main outflow pathways in the WTB/FBC/ 

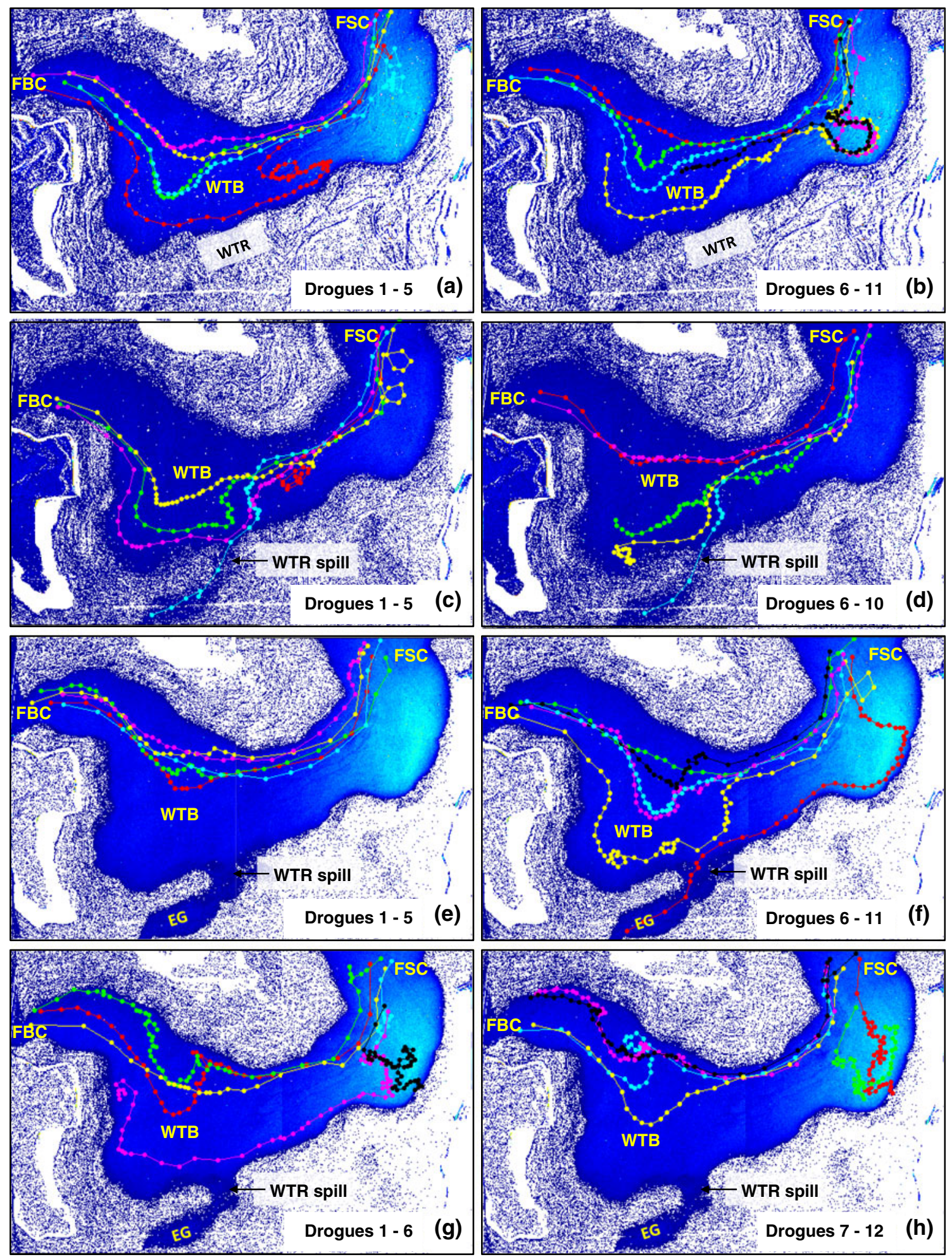

Fig. 6 Typical drogue tracking for dense water outflow layer in Faroese Channels region under investigation for runs with $\mathrm{Bu}_{1}: Q_{1}^{*}$ values of $\mathbf{a}-\mathbf{b}$ $0.363: 1.9 \times 10^{-4}$ (run 3b, Table 1); c-d 0.202:1.26 $\times 10^{-3}$ (run 2c); e-f $0.114: 5.99 \times 10^{-3}$ (run 5c); $\mathbf{g}$ h 0.110:4.49 $\times 10^{-3}$ (run 5b). Time step between

WTR region is assembled from these recorded drogue tracks (Fig. 8), showing the approximate regions within the plotted drogue positions $\Delta t=0.42 \mathrm{~s}$ (every ten image frames @ 24 fps). Background images show fluorescene-dyed overflow pathways for equivalent runs

topographic model where positive and negative vorticity regions (or circulations) were observed. Direct comparisons 

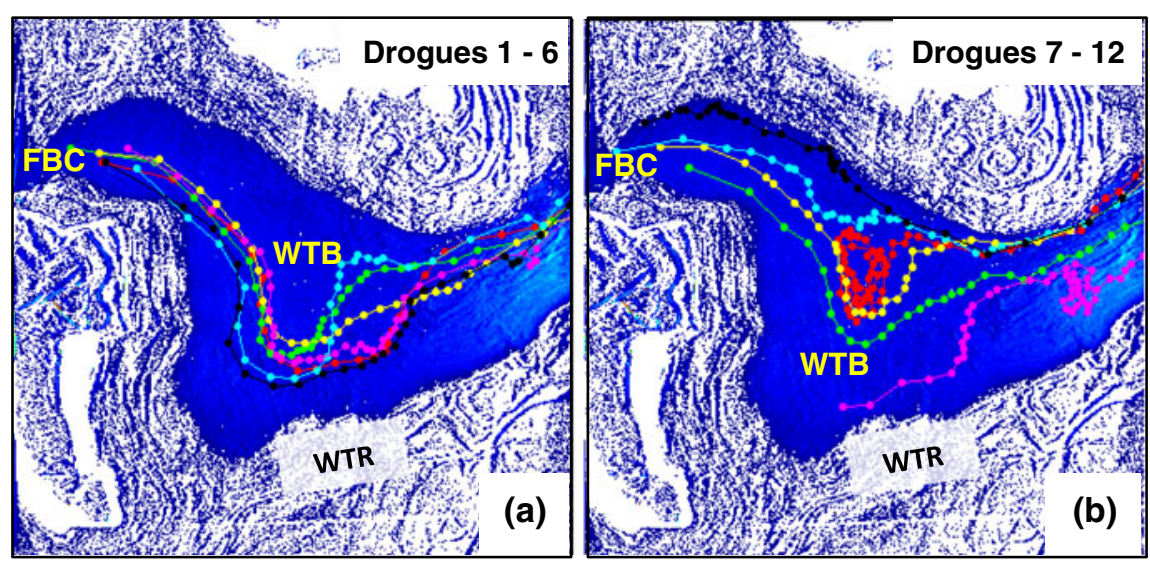

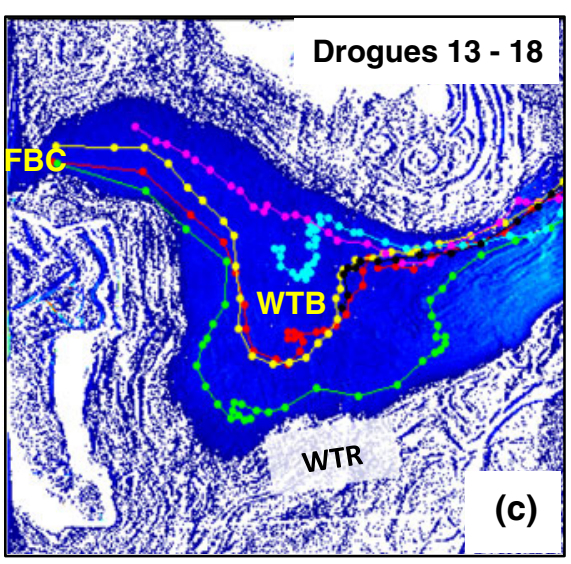

Fig. 7 Typical drogue tracks showing circulation paths in dense water overflow in the converging, up-sloping approach to the FBC sill. Plots a-c show 18 drogue trajectories in the WTB/FBC approach for run $6 \mathrm{~b}$

between these experimental observations and the Massachusetts Institute of Technology General Circulation Model (MITgcm) numerical predictions of similar flow pathways and closed circulations within the FBC/WTB topography are discussed in detail in Sections 6 and 7 of the paper.

\subsection{Density measurements}

Time series density profiling data was obtained at three crosschannel transects (S1-S3, Fig. 2) within the WTB and the upsloping, converging approach to the FBC, allowing the dynamic evolution of the dense outflowing bottom-water layer to be observed throughout each experimental run. From these density data, time-averaged isopycnal elevations [defined by the density excess contours $\left.\rho^{\prime}=\left(\rho-\rho_{0}\right) /\left(\rho_{1}-\rho_{0}\right)=0.1 \rightarrow 0.9\right]$ could be plotted along each transect for the quasi-steady-state outflow conditions that were developed in the modelled channel bathymetry under each parametric condition (Table 1). Figure 9 shows typical isopycnal elevations measured along
(Table 1) with $\mathrm{Bu}_{1}: Q_{1}^{*}$ values of $0.199: 8.7 \times 10^{-4}$. Time step between plotted drogue positions $\Delta t=0.42 \mathrm{~s}$. Background images show fluorescene-dyed overflow pathways for equivalent run

transects S1, S2 and S3 for runs with different Burger numbers $\mathrm{Bu}_{1}$ and discharge parameter $Q_{1}^{*}$ values, for the range of parametric conditions $\left(Q_{1}, g^{\prime}, f\right)$ considered (see Table 1$)$.

Two interesting features from the cross-sectional isopycnal elevation plots along transects S1 and S2 are observed (Fig. 9), specifically: (i) an undulating variability in isopycnal elevation with cross-channel distance, with isopycnal lifting and sinking observed at different measurement locations along the transect and (ii) the "pinching" of isopycnals on the left (WTR) side of the basin. The undulations in the isopycnal structure are more apparent on transect $\mathrm{S} 1$ and for parametric runs at lower $Q_{1}$ values [i.e. isopycnal group (ii) at transect S1; Fig. 9a, b], tending to diminish somewhat in the along-channel direction and for runs at higher $Q_{1}$ values [i.e. isopycnal group (i) at transect S2; Fig. 9a, b]. However, it is noted that this property of the isopycnal field remains a distinct feature at transect S1 for all parametric conditions tested and is attributed to the presence of the closed circulation forming at the entrance to the converging, up-sloping
Fig. 8 Schematic representation of dense water outflow pathways from drogue-tracking measurements. Solid and dashed lines main and secondary pathways, respectively. Shaded areas main regions where vorticity (positive and negative) was observed. Abbreviations for prominent seabed features as detailed in Fig. 1 caption

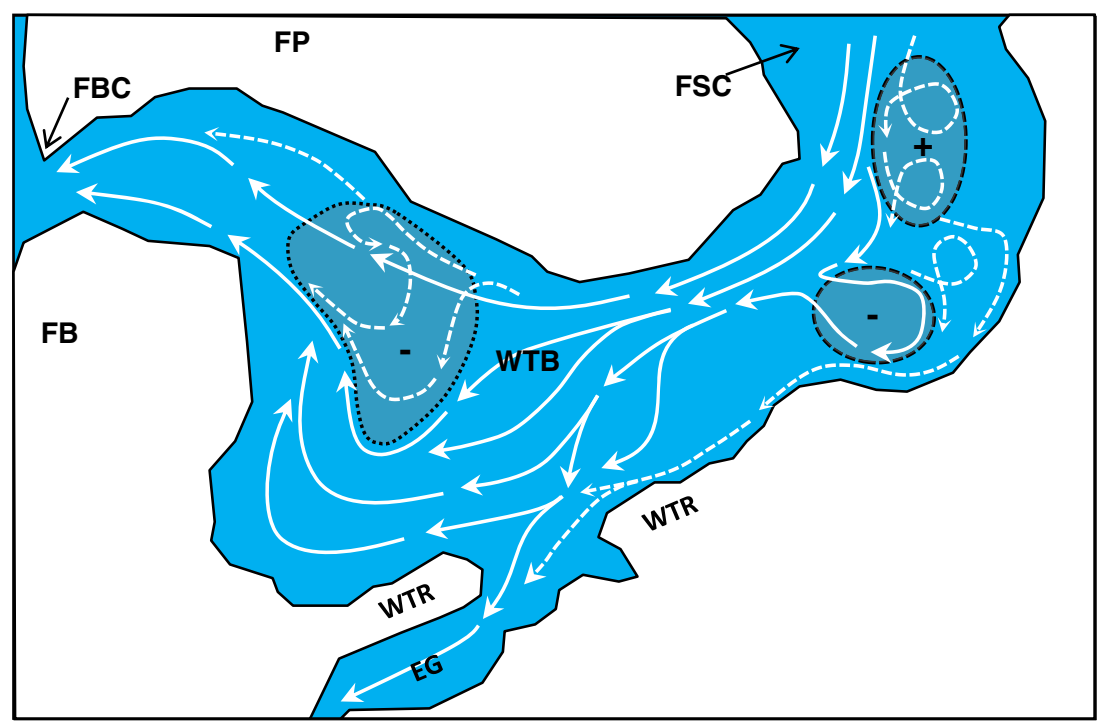



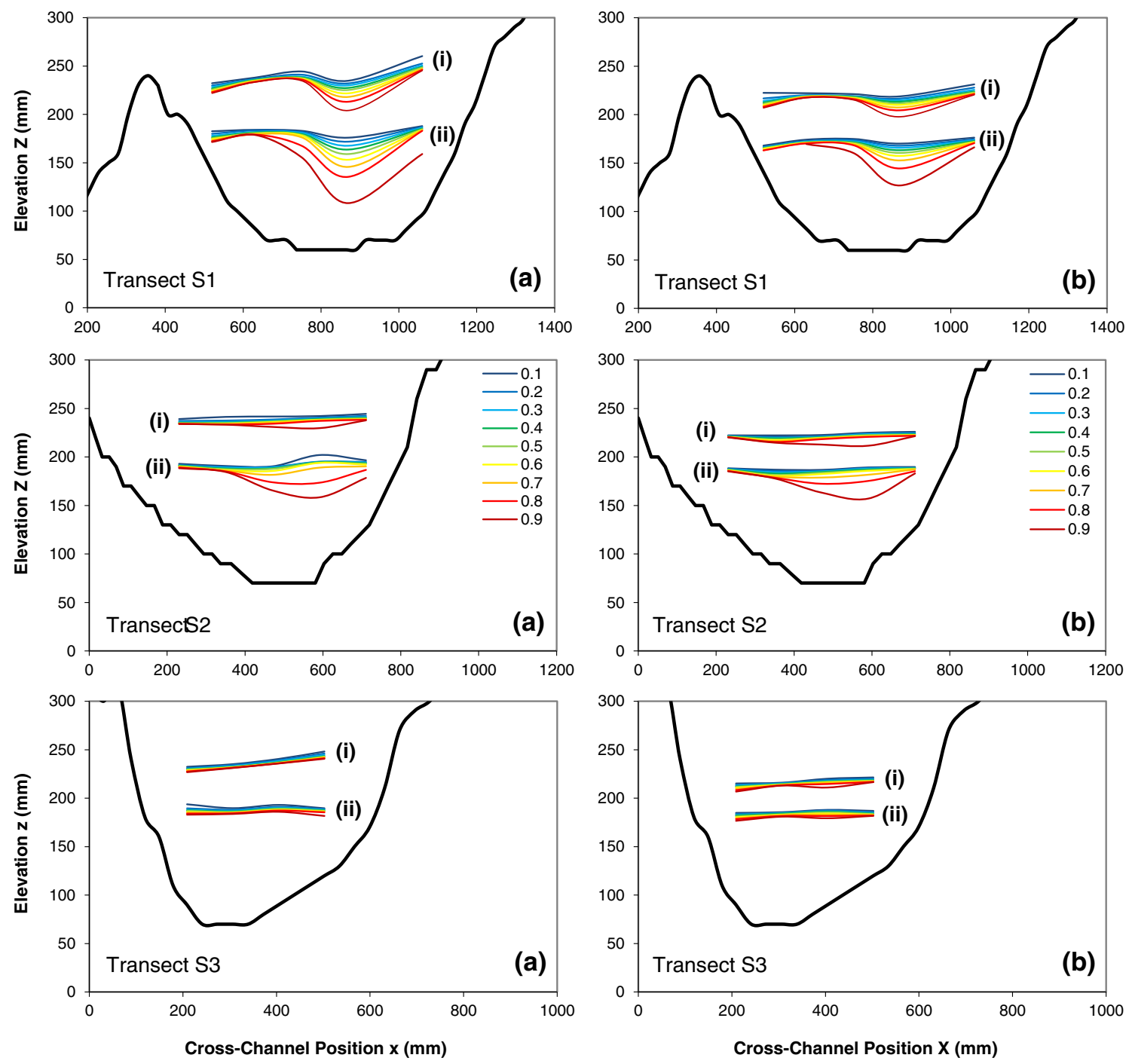

Fig. 9 Cross-channel isopycnal $\left(\rho^{\prime}=0.1-0.9\right)$ elevations at transects S1-S3 (see Fig. 2 for transect locations) for the parametric conditions specified in a run 1 and $\mathbf{b}$ run 3 (see Table 1). The specific pycnocline

approach to the $\mathrm{FBC}$, which transect $\mathrm{S} 1$ is shown to intercept (see Section 7).

It is also noted from the density measurements along transect S1 that the upper boundary of the dense outflowing water layer displays a general tilt towards the left (WTR) side of the basin, especially for runs conducted under higher $Q_{1}$ conditions [i.e. isopycnal group (i) at transect S1; Fig. 9a, b]. This inclination may be attributed partly to the parametric influence of background rotation $\Omega$ in the geostrophic adjustment of the bottom outflowing layer and/or the initiation of dense water spillage across the WTR under higher $Q_{1}$ conditions, acting to control isopycnal elevations at the WTR side of transect S1 (note: this transect is located immediately downstream of the region of minimum bed elevation along the WTR where the dense water spillage occurs; see Fig. 2).

In comparison to the relatively complex isopycnal structure observed along transects S1 (and, to a lesser extent) S2, the

plots shown at each transect are for $\mathrm{Bu}_{1}: Q_{1}^{*}$ values of $\mathbf{a}$ (i) $0.115: 9.15 \times$ $10^{-3}$ (run 1d), (ii) $0.124: 3.52 \times 10^{-3}$ (run 1a), b (i) $0.343: 3.4 \times 10^{-4}$ (run 3d) and (ii) $0.368: 1.3 \times 10^{-4}$ (run 3a)

corresponding density measurements obtained along transect S3 indicate the development of a sharp pycnocline, with no indication of a wedge-type distribution of isopycnals across the transect. The degree of inclination observed in these isopycnal distributions (downwards to the FB side of the channel; see Fig. 3) is controlled by geostrophic adjustment in the outflowing bottom layer along the up-sloping, converging FBC approach channel. Direct comparison between the two isopycnal groups [(i) and (ii)] shown in the separate $\mathrm{S} 3$ transect plots of Fig. 9a, b indicates that, for otherwise identical parametric conditions (stratification $g^{\prime}$ and rotation $f=2 \Omega$ ), the pycnocline is inclined to a greater degree for larger $Q_{1}^{*}$ values (i.e. through a larger specified initial volume flux $Q_{1}$ at the FSC inlet boundary). In addition, comparison between equivalent S3 isopycnal groups [(i) or (ii)] in Fig. 9a,b, also indicates that increased pycnocline tilt is also achieved by a reduction in the inlet Burger number $\mathrm{Bu}_{1}$ (i.e. by reducing $g^{\prime}$ at the inlet, for 
otherwise equivalent parametric conditions). A similar parametric dependence is displayed for isopycnal tilt from changing the background rotation rate $\Omega$ (i.e. an increase in $f=2 \Omega$, resulting in a reduction in $\mathrm{Bu}_{1}$, leads to an increasing pycnocline tilt in the FBC approach channel). In this sense, these parametric dependences of $g^{\prime}$ and $f$ are in accord with those expected for geostrophically balanced outflows, where the cross-channel geostrophic slope $\alpha_{g}$ of a sharp pycnocline forming between the dense outflow layer and upper ambient layer can be approximated by $\alpha_{g} \approx v_{1} f / g^{\prime}$ (where $v_{1}$ is the average streamwise velocity in the dense outflowing layer). Hence, an increase in either outflow velocity (i.e. through $Q_{1}$ ) or background rotation (i.e. through $f$ ), and/or a reduction in density stratification (i.e. through $g^{\prime}$ ) is therefore expected to increase the cross-channel inclination of the pycnocline along the converging, up-sloping channel. Similar geostrophic dependencies were also demonstrated in laboratory experiments of dense water overflows in simpler rotating, up-sloping and converging channel topographies (Cuthbertson et al. 2011, 2013).

\section{MITgem numerical model}

\subsection{Model set up}

Numerical simulations of the deep water outflow pathways and circulations within the Faroese Channels were conducted within a similar restricted model domain to that used in the scaled laboratory model (Fig. 2). In order to facilitate direct comparison with experimental measurements, the numerical simulations were conducted for the same vertically distorted, scaled seabed topography as adopted for the laboratory model. Consequently, the numerical model domain had overall dimensions $L_{x} \times L_{y} \times L_{z}=2.5 \mathrm{~m} \times 2.2 \mathrm{~m} \times 0.4 \mathrm{~m}$, where $L_{x}, L_{y}$ and $L_{z}$ represent the scaled lengths of the NW/SE, NE/SW and vertical directions, respectively. As with the scaled, physical model, this numerical model domain orientation was chosen to ensure the incoming dense water from the FSC is constrained at the inlet boundary by the natural topographic barriers presented by the Scotland and Faroe shelves. Similarly, the outlet model boundaries at the FBC and EG were also constrained by the FP/FB and FB/YR topography, respectively (see Fig. 1).

Prediction of the dense outflow dynamics within the scaled topographic model was conducted using the MITgcm (Marshall et al. 1997). The model uses a Cartesian system of coordinates $0 x y z$, with the $0 x y$ plane parallel to the undisturbed free surface and the $0 z$-axis directed vertically upward. The $0 x$ and $0 y$-axis are directed along the boundaries of the model domain (Fig. 2). The numerical simulations were conducted on a fine-resolution grid with horizontal steps $\Delta x=\Delta y=$ $0.025 \mathrm{~m}$ and a vertical step $\Delta z=0.005 \mathrm{~m}$. The coefficients of horizontal and vertical viscosity and diffusivity were taken typical for a laminar range of fluid flows, i.e. $10^{-6} \mathrm{~m}^{2} \mathrm{~s}^{-1}$.

The methodology for running the numerical simulations is described in detail in Stashchuk et al. (2010, 2011). At the "cold-start" initiation time $(t=0)$ for each run, a lock gate at the FSC inlet boundary was removed and an inflow of dense bottom water of prescribed density was forced into the numerical model domain by the generated pressure gradient, with a typical inflow velocity of $0.15 \mathrm{~ms}^{-1}$. The inlet lower layer depth $h_{1}$ and velocity $v_{1}$ (hence, volume flux $Q_{1}$ ) were set constant throughout the whole run time (700 s, typically), with their prescribed magnitudes set for the specific parametric conditions under investigation (see Table 1). Orlanski-type boundary conditions (Orlanski 1976) were specified along the other three boundaries of the model domain, whilst the flow at the bottom satisfied a non-slip boundary condition.

The resulting outflow pathways for the propagation of dense water through the model domain is visualised through an extra equation for passive tracer transport. A tracer concentration of $\tau=1$ is prescribed for pure, undiluted dense bottom water, decreasing from $\tau=1$ to 0 across the pycnocline separating the bottom gravity current from the overlying ambient water mass.

\subsection{Details of parametric model runs}

A total of five experimental runs were simulated using MITgcm (runs 2b, 3c, 5b, 6b and 6c; Table 1). This allowed the model sensitivity to different parametric conditions (defined by $\mathrm{Bu}_{1}=$ $0.363,0.202,0.199,0.110$ and 0.114 ; and $Q_{1}^{*}=0.19 \times 10^{-3}$, $1.26 \times 10^{-3}, 0.87 \times 10^{-3}, 4.49 \times 10^{-3}$ and $5.99 \times 10^{-3}$, respectively) to be investigated. For each numerical simulation, the evolution and development of the outflowing dense water layer within the scaled model domain was simulated over a total duration of $700 \mathrm{~s}$, allowing quasi-steady state outflow pathways and circulations to be established within the modelled topography. For each set of parametric conditions modelled, the generated pathways and circulations were characterised within the Faroese Channel domain through (i) simulated passive dye tracing, (ii) modelled $x y$ velocity vector fields and drogue tracks and (iii) predicted density fields.

\subsection{Model comparisons with experiments}

Due to the complex nature of the dense water outflow within the topographic region under consideration, direct comparisons between experimental data and numerical simulations were largely limited to qualitative observations, with emphasis placed on modelling accurately (1) the scaled, FSC inlet parametric boundary conditions; (2) the development of quasi-steady-state dense water outflow pathways and circulations within the FSC/WTB/FBC topography and (3) the conditions under which spill and no-spill occur across the WTR. 
In particular, the modelled dense water outflow conditions achieved at the end of each simulation were compared with (1) experimentally observed dye traces for dense water outflow pathways and the parametric conditions for spillage across the WTR (Figs. 4 and 5); (2) general observations on deep-water circulations established from drogue-tracking experiments (Figs. 6 and 7) and (3) density field measurements obtained at the transect S1 in the WTB (Fig. 9).

Figure $10 \mathrm{a}-\mathrm{c}$ show MITgcm-predicted dye traces (left images) in the lower outflowing layer for a range of parametric conditions (runs $2 \mathrm{~b}, 3 \mathrm{c}$ and $5 \mathrm{~b}$; Table 1) and corresponding experimental dye traces (right images) measured under the same parametric inlet conditions (i.e. $\mathrm{Bu}_{1}$ and $Q_{1}^{*}$ values). In all cases, the simulated passive dye traces show excellent agreement with the corresponding experimental observations, especially with regards to the parametric conditions under which the initiation of dense water spillage across the WTR occurs [e.g. $\mathrm{Bu}_{1}: Q_{1}^{*}=0.202: 1.26 \times 10^{-3}$ (run 2c); Fig. 10b]. In addition, both experimental and numerical dye traces show qualitatively similar outflow pathways through the FBC for parametric conditions under which no WTR spill occurs [e.g. $\mathrm{Bu}_{1}: Q_{1}^{*}=0.363: 0.19 \times 10^{-3}$ (run $3 b$ ) and 0.199: $0.87 \times 10^{-3}$ (run 6b); Fig. 11a, c, respectively]. In this sense, the numerical dye simulations appear to reinforce the proposed parametric relationships between the $Q_{1}^{*}, \mathrm{Bu}_{1}$ and $h_{1} / l_{1}$ (see Fig. 5), delineating the range of deep water overflow conditions where WTR spillage is expected to occur.

Figure 11 shows MITgcm-predicted $x y$ velocity vector fields computed after $500 \mathrm{~s}$ at two depths (i.e. 20 and $25 \mathrm{~cm}$ beneath the free surface boundary) for all parametric conditions tested. These velocity fields demonstrate clearly the effect of the Coriolis force on the dense water outflow entering the scaled Faroese Channel model domain, with the boundary current (particularly evident at $25 \mathrm{~cm}$ depth) shown to follow the Faroese shelf edge as it propagates from the FSC through the $90^{\circ}$ converging transition into the WTB. Some evidence of cyclonic and anti-cyclonic eddy formation is observed in the FSC at $20 \mathrm{~cm}$ depths (Fig. 12a, c and e) but these appear largely absent at $25 \mathrm{~cm}$. Within the WTB, the deep-water outflow is shown to detach from the FP side of the basin and appears to be deflected towards the WTR, with spillage across the WTR (evident in $20 \mathrm{~cm}$ depth plots; Fig. 11). This detachment and deflection towards the WTR is, evidently, the result of a flow separation process associated with the generation of a large anti-cyclonic eddy in the WTB and converging approach to the FBC (most evident in the $20 \mathrm{~cm}$ depth plots; Fig. 11), which is also shown to influence strongly the pathways for $\mathrm{FBC}$ overflows (i.e. continuing to flow along the WTR and FB before spilling out through the FBC). In contrast, the presence of this large anti-cyclonic eddy decreases at greater depths (i.e. $25 \mathrm{~cm}$ plots; Fig. 11), with the resulting outflow pathways towards the FBC showing lesser influence from flow separation and circulations in the WTB/FBC approach channel (i.e. flowing through the WTB in paths closer to the FP). Overall, these simulated velocity fields are in good qualitative agreement with observed bottom water circulations, as indicated by the experimental drogue track measurements (see Figs. 6 and 7). Indeed, these experimental and numerical runs indicate that observed and predicted cyclonic and anti-cyclonic circulations occur at approximately the same $x y$ locations within the lower dense water layer and have similar influence on the outflow pathways to the FBC and across the WTR. In addition, comparing the MITgcm predictions for the different parametric conditions tested, the runs conducted with lower inlet $Q_{1}$ values [i.e. runs $2 \mathrm{~b}, 5 \mathrm{~b}$ and $6 \mathrm{~b}$; Fig. 12a, c and e, respectively] generate more significant eddy motions at $20 \mathrm{~cm}$ depths than runs with higher inlet $Q_{1}$ values [i.e. runs $3 \mathrm{c}$ and $6 \mathrm{c}$; Fig. 12b, d, respectively]. The main reason for this behaviour is that increased eddy circulations are generated closer to the pycnocline, between the dense outflowing bottom waters and the overlying ambient fluid, than at greater depths within the lower layer. In the experiments, it was not possible to ascertain individual drogue elevations within the outflowing dense water layer, so that the recorded variability in observed drogue paths under the same parametric conditions may have arisen from variability in drogue elevations relative to the pycnocline. Indeed, comparing the measured drogue trajectories in Fig. 6e, f with the predicted velocity vector fields in Fig. 11d (i.e. under the same parametric conditions) shows that the drogues released in Fig. 6e may have tracked the outflowing layer at an elevation similar to the $25 \mathrm{~cm}$ depth velocity vector plot (Fig. 11d). By contrast, the drogue tracks in Fig. 6f appear to be more qualitatively similar to the $20 \mathrm{~cm}$ depth velocity vector plot (Fig. 11d) and may be more representative of lower-layer drogue trajectories close to the pycnocline.

Figure 12 shows the evolution of the MITgcm-predicted density field across the WTB transect at the location corresponding to the lowest elevation along the WTR (see Fig. 2). The parametric simulations shown correspond to relatively moderate values of the controlling parameters, with $\mathrm{Bu}_{1}: Q_{1}^{*}=$ 0.110:0.00449 (run 5b) and 0.114:0.00599 (run 5c) in Fig. 12a, b, respectively. Both test simulations reveal the process of evolution within the cross-channel structure of the density field during the first $700 \mathrm{~s}$ after the lock release at the FSC inlet boundary. It is observed clearly that, as for the laboratory experiments along transect S1 (Fig. 9), the isopycnal surfaces are generally tilted towards the left (WTR) side of the basin. This inclination is greatest in the beginning of the experiment when the dense water begins initially to fill the basin [i.e. at $t=150 \mathrm{~s}$, Fig. 12a, b] and remains visible at the end of the adjustment period (i.e. at $t=700 \mathrm{~s}$ ) when substantial dense water spillage is observed across the WTR. In the corresponding experimental runs, the measured pycnocline was shown generally to remain relatively sharp between the dense outflowing water and overlying ambient water layers, except in 

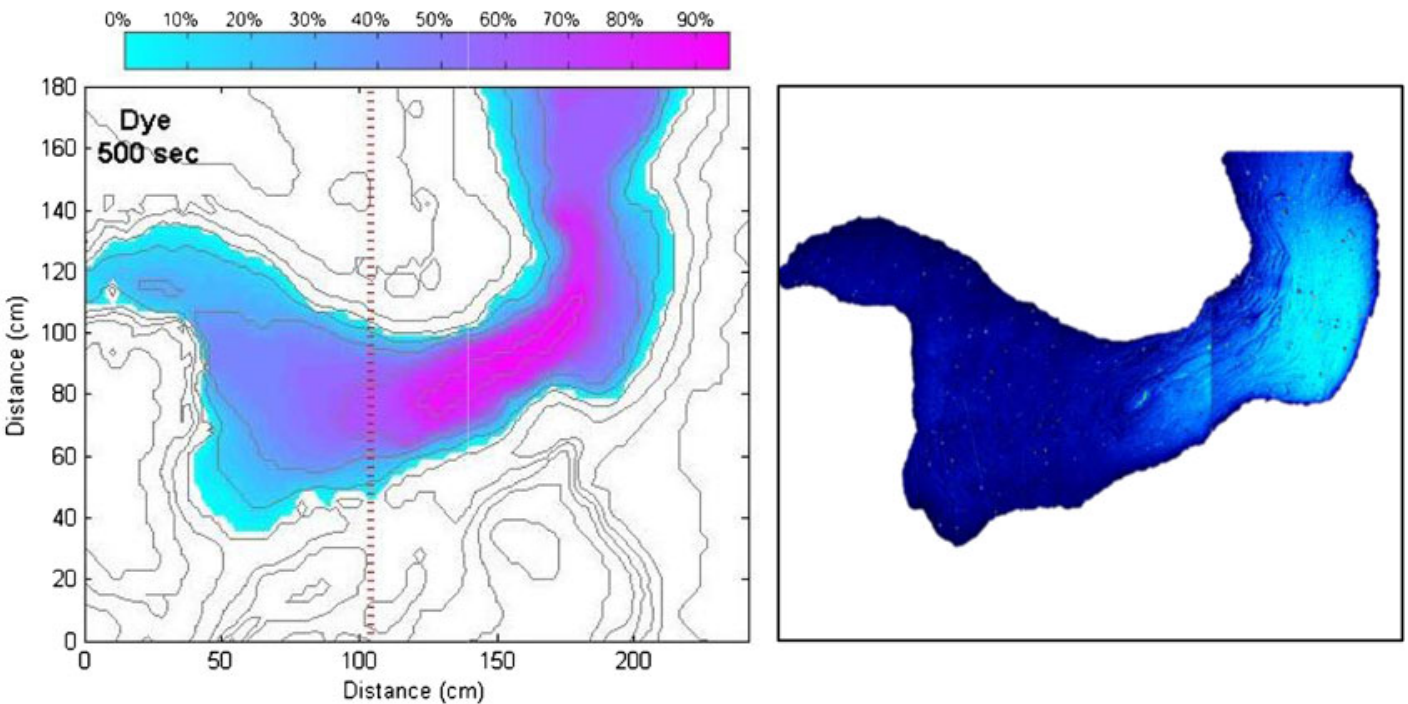

(a)
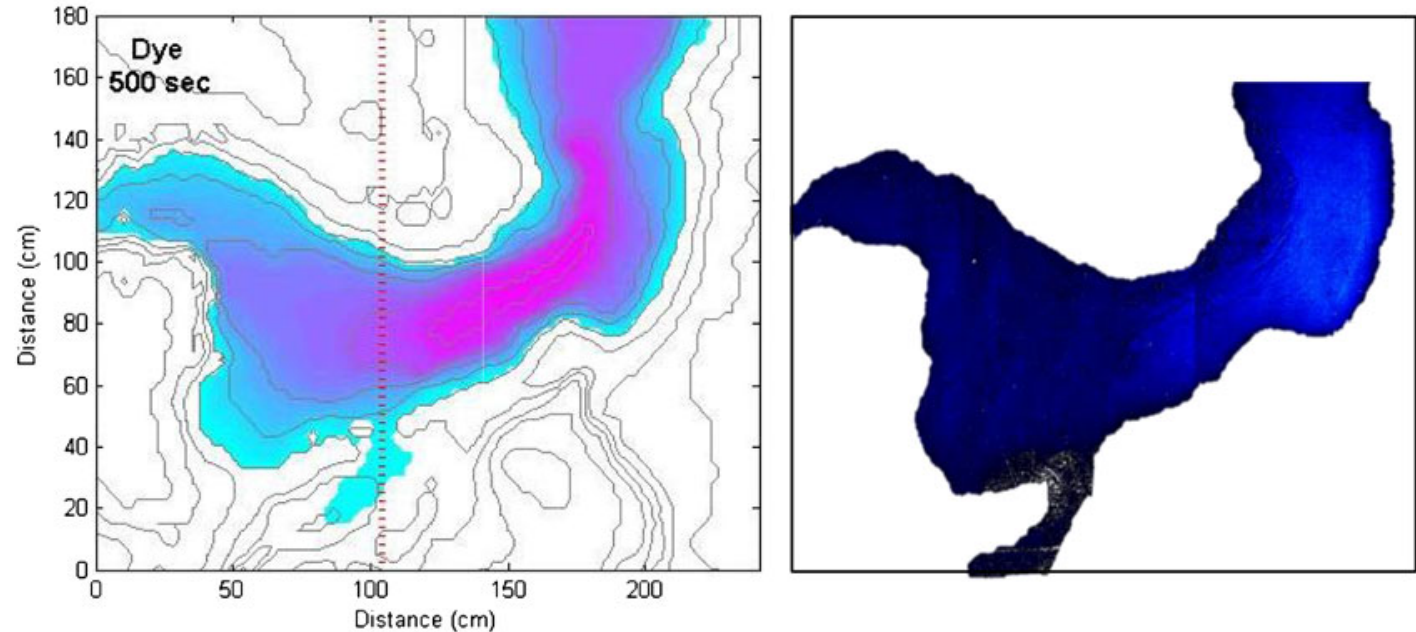

(b)
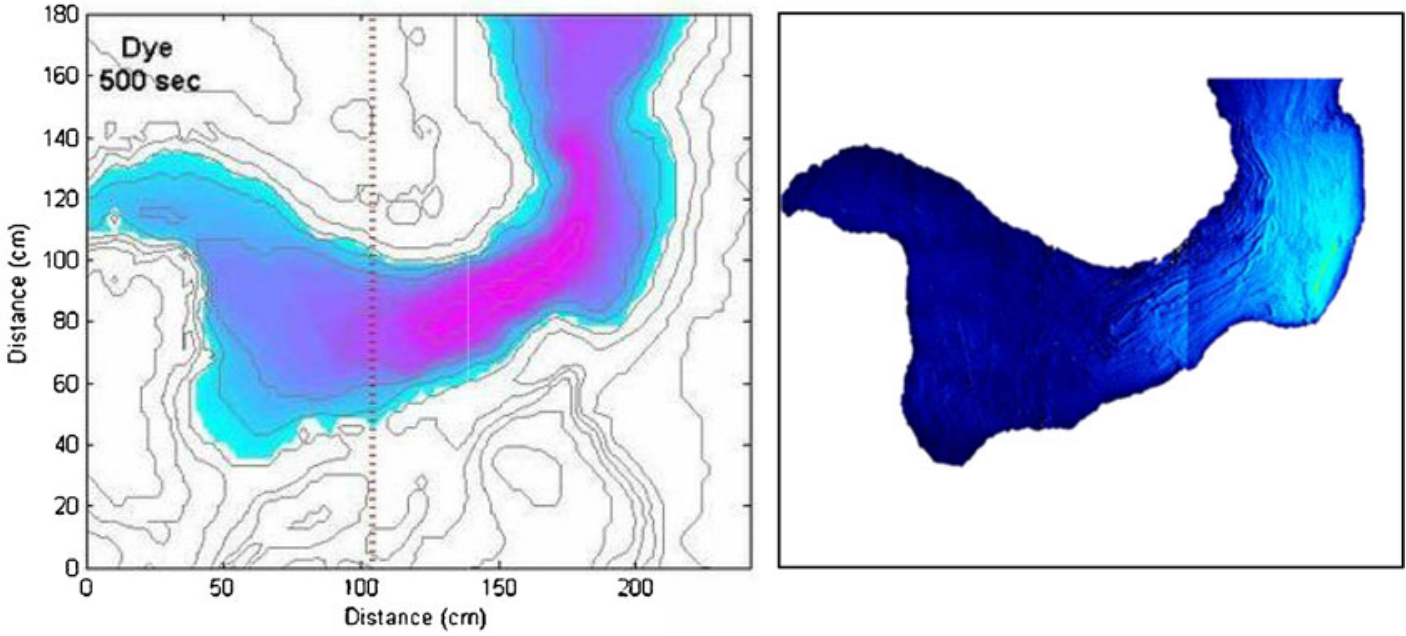

(c)

Fig. 10 Comparison of MITgcm-predicted (left) and measured (right) dyed bottom-water traces through Faroese channel topography for $\mathrm{Bu}_{1}$ : $Q_{1}^{*}$ values of a 0.363:0.00019 (run 3b; Table 1), b 0.202:0.00126 (run 2c)

and c 0.199:0.00087 (run 6b). Colour scale on numerical predictions represents tracer concentration $(0 \%$, initial basin concentration; $100 \%$, undiluted deep water tracer concentration at the FSC inlet boundary) 
Fig. 11 MITgem predictions of velocity vector fields at 20 and $25 \mathrm{~cm}$ depths for $\mathrm{Bu}_{1}: Q_{1}^{*}$ values of a 0.363:0.00019 (run 3b; Table 1), b 0.202:0.00126

(run 2c), c 0.199:0.00087 (run 6b), d 0.114:0.00599 (run 5c) and e 0.110: 0.00449 (run 5b).

Velocity vector scales as shown in figure
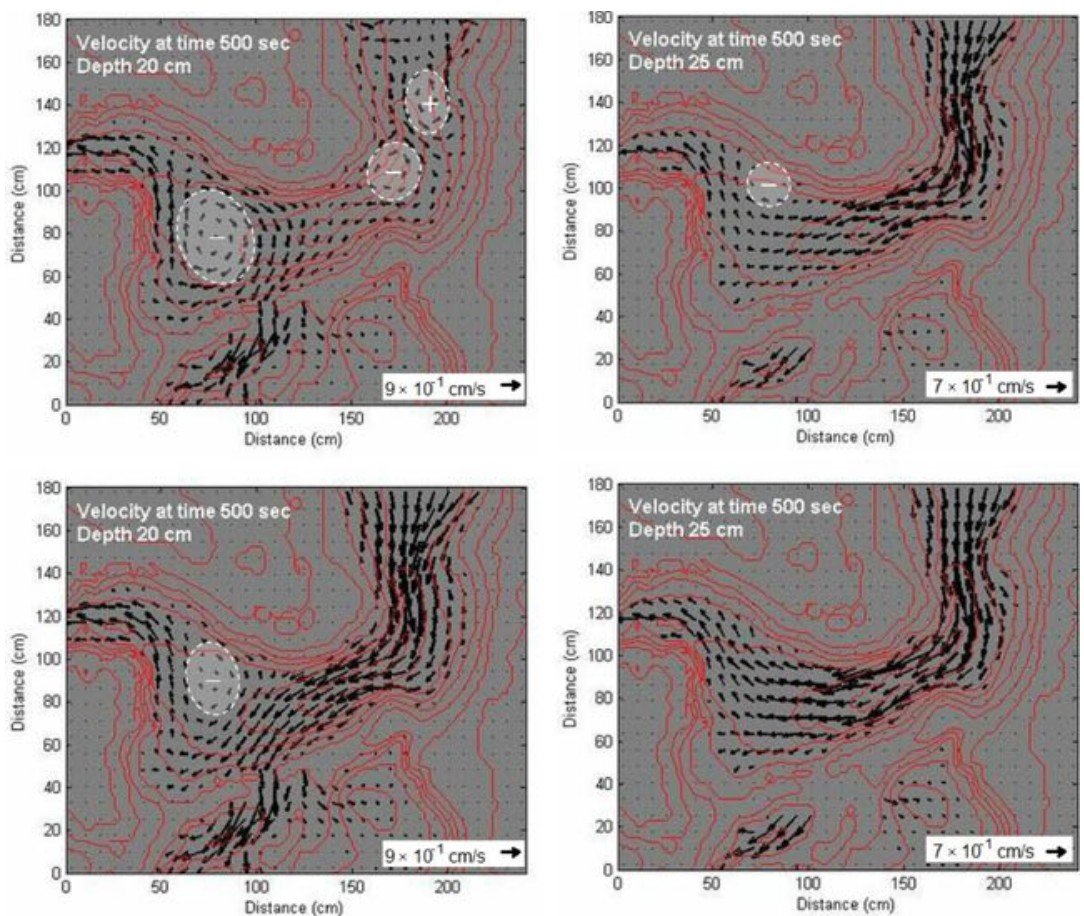

(a)
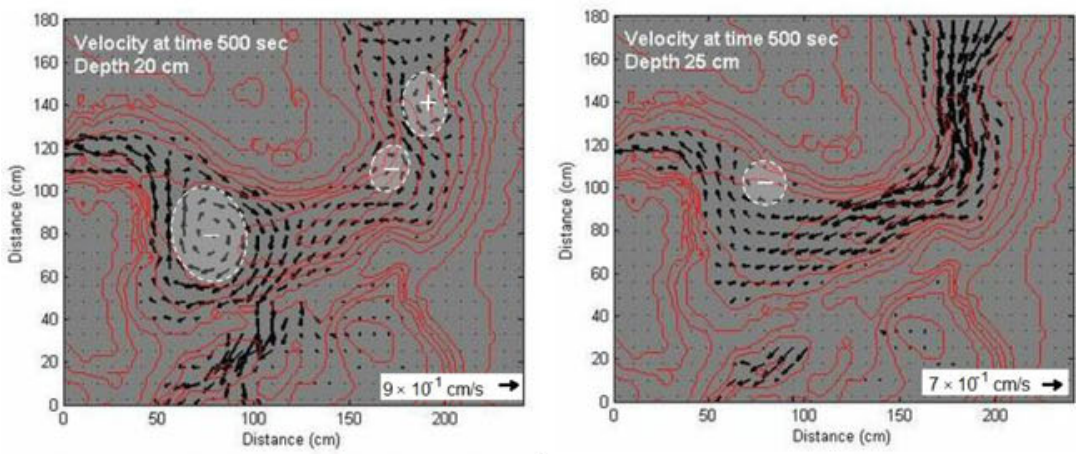

(b)
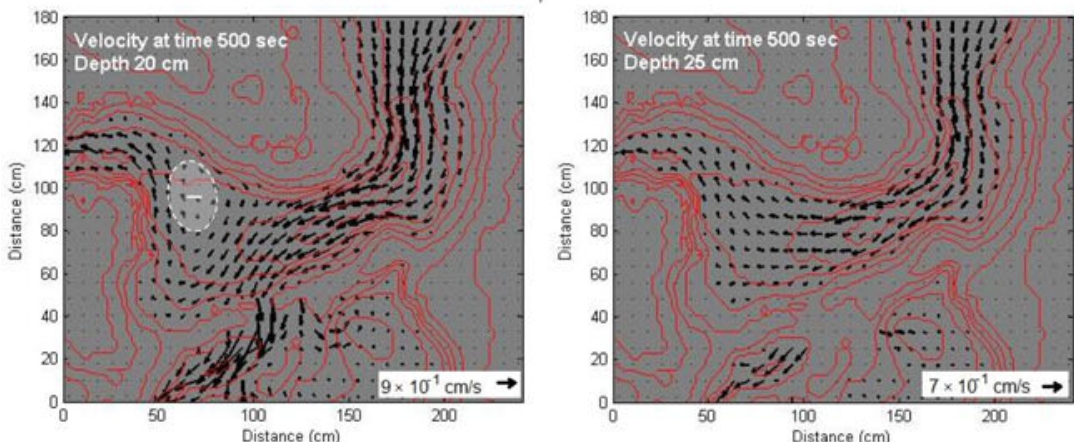

(c)
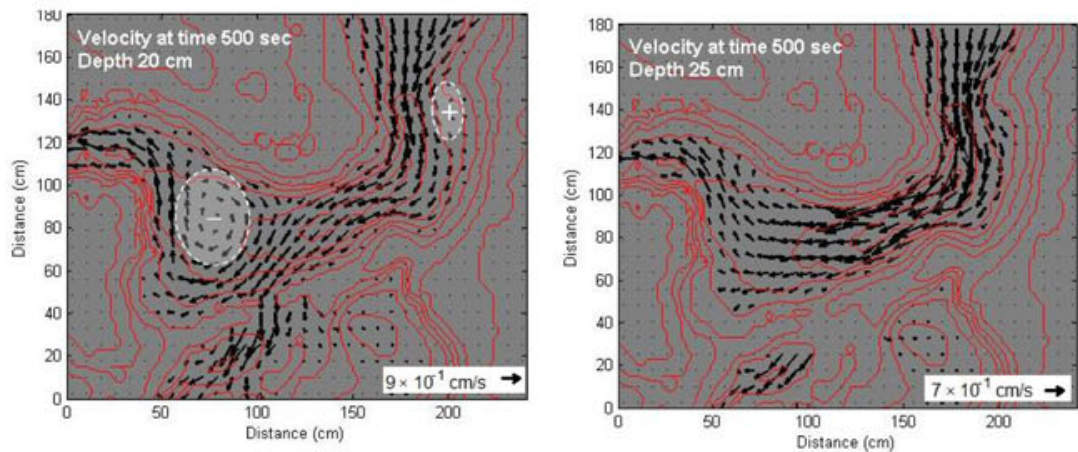

(d)

(e) 


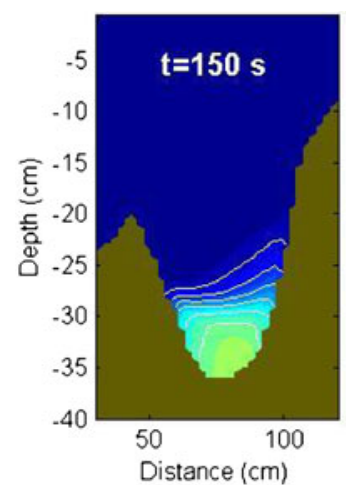

Distance $(\mathrm{cm})$

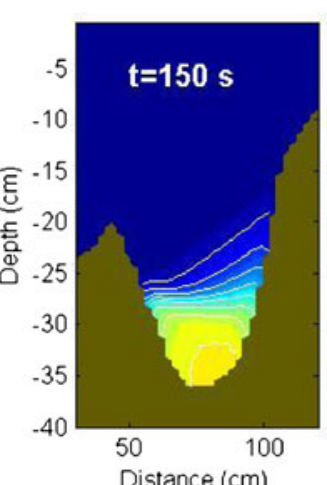

Distance $(\mathrm{cm})$

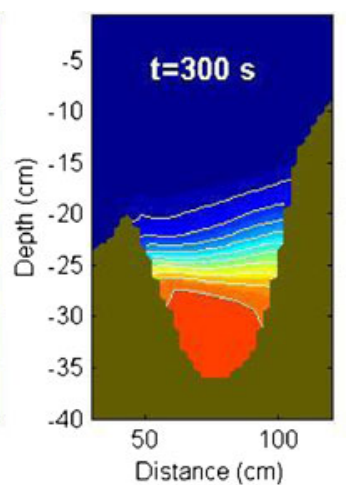

Distance $(\mathrm{cm})$

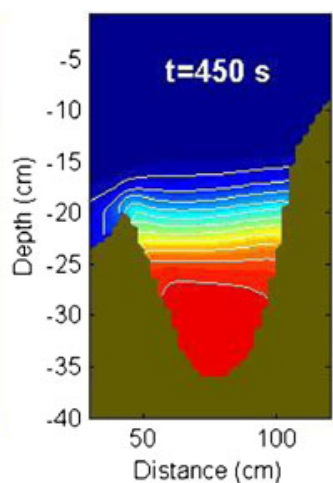

(a)

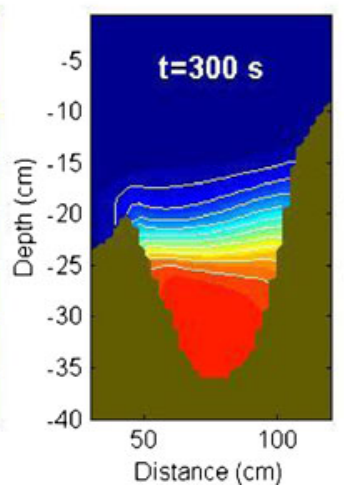

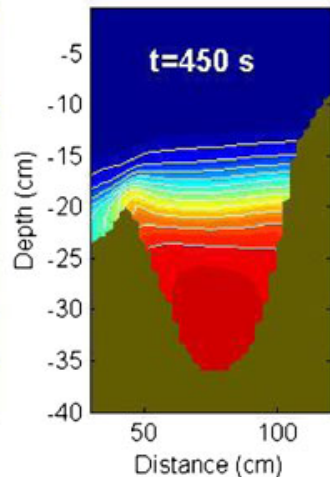

(b)

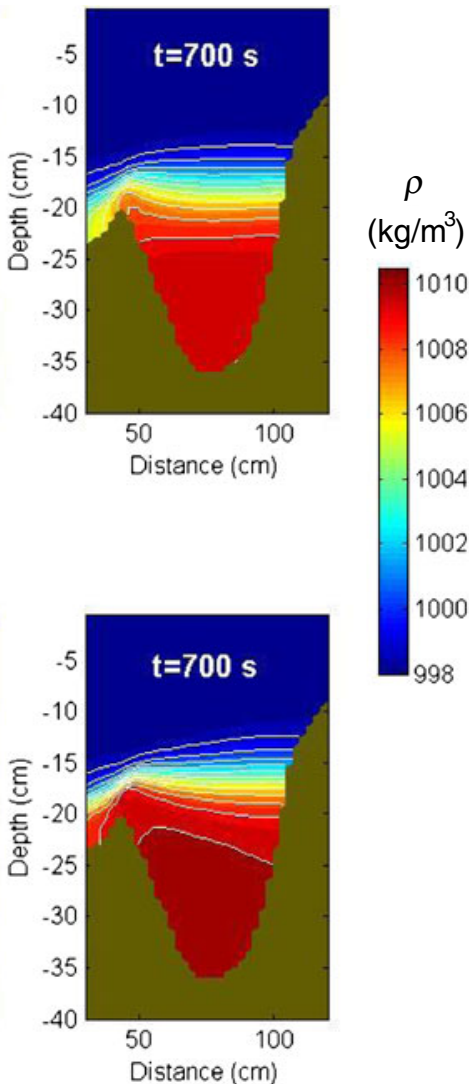

Fig. 12 MITgcm-predicted temporal evolution of the density field across WTB transect (dotted white line, Fig. 2) for Bu $\mathrm{Bu}_{1}: Q_{1}^{*}$ values of a 0.110:0.00449 (run 5b; Table 1) and b 0.114:0.00599 (run 5c). Colour scale represents water density $\rho$ (in kilograms per cubic meter)

regions were strong anti-cyclonic circulations were generated at the entrance to the converging, up-sloping approach to the FBC (e.g. transect S1; Fig. 9). This particular feature of isopycnal divergence is discussed in Section 7 below.

\section{Summary and conclusions}

A combined experimental and numerical study has been conducted to improve understanding of the mesoscale dynamics and structure of the NSDW through the Faroese Channels and the conditions under which spillage across the WTR can occur. The laboratory experiments and MITgcm numerical simulations were conducted in equivalently scaled, vertically distorted representations of the seabed topography in the region of interest. Both experimental observations and numerical predictions indicated that the majority of dense water originating in the FSC propagated towards the FBC as the main outflow pathway. However, a range of parametric conditions were also replicated where an additional outflow pathway was initiated through the depression in the WTR, with this dense water overflow propagating subsequently down through the Ellett Gully. Dimensional analysis revealed that three non-dimensional parameters, namely the Burger number $\mathrm{Bu}_{1}$, a volume flux parameter $Q_{1}^{*}$ and the deep water inflow length ratio $h_{1} / l_{1}$, specified at the inlet boundary within the FSC, act as controlling variables determining whether secondary overflow across the WTR is initiated. Both experimental observations and numerical simulations of passive dye tracing within the lower outflowing layer are in accord with the proposed $Q_{1}^{*}: \mathrm{Bu}_{1}$ and $Q_{1}^{*}: h_{1} / l_{1}$ regime plots for WTR spill and nospill conditions. Furthermore, the fact that the inlet volume flux $Q_{1}$ appears to play the most significant parametric role in the initiation of dense water spillage across the WTR suggests that the topographic constriction and hydraulic control imposed at the FBC outlet sill may act to limit the volume flux passing through the FBC, in turn controlling the dimensions $\left(h_{1}, l_{1}\right)$ of the inflowing dense water layer at the FSC inlet.

One of the key features of both the experimental observations and numerical simulations is the generation of cyclonic and anti-cyclonic eddies and gyres within the Faroese Channels. These features have been shown to have a significant influence on dense water outflow pathways as well as in promoting spillage across the WTR. The formation of these flow re-circulations (and the large anti-cyclonic eddy generated upstream of the FBC in particular) are associated clearly 

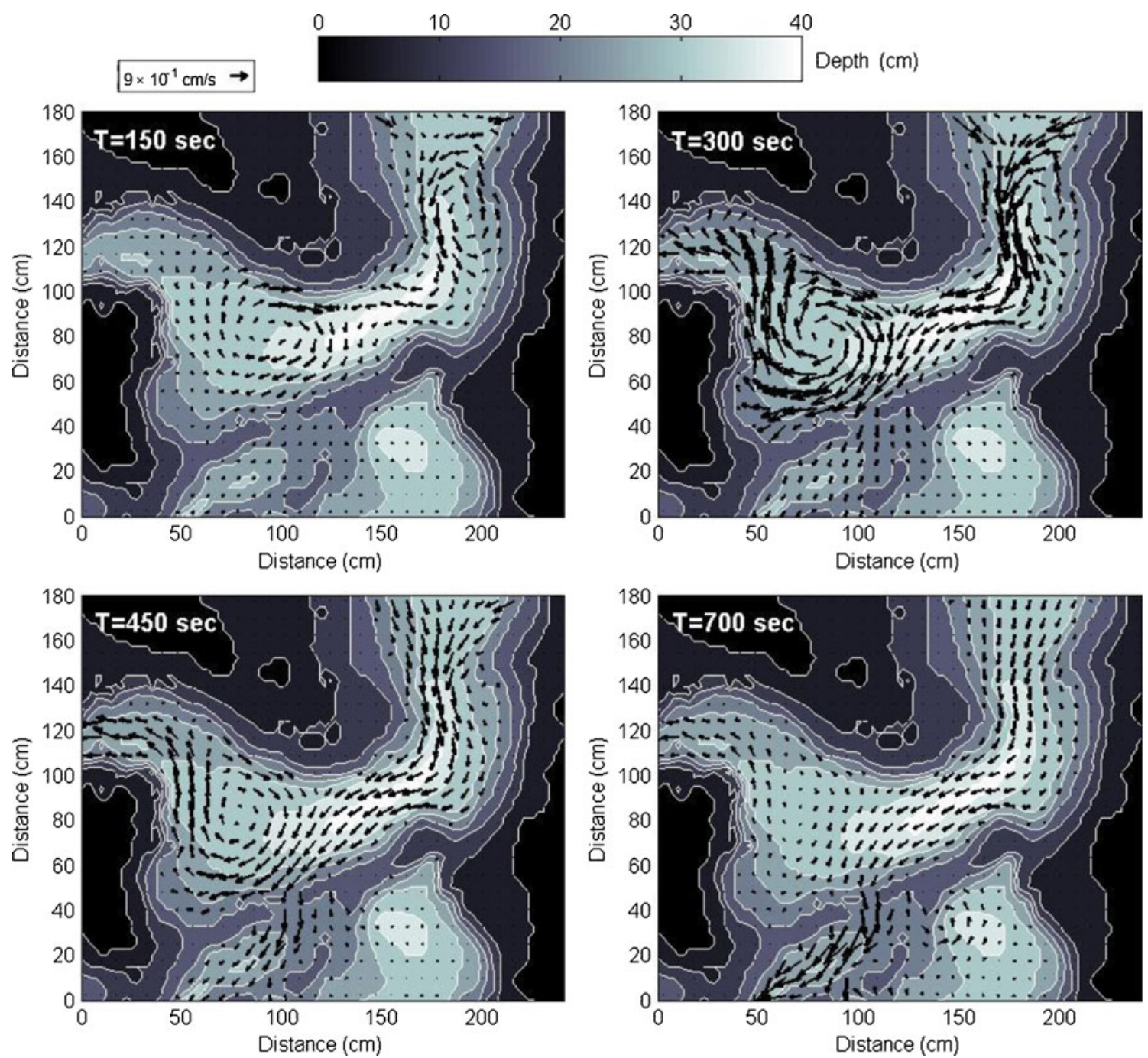

Fig. 13 MITgcm-predicted evolution in the velocity field at the depth of the scaled WTR ridge depression (20 cm) for $\mathrm{Bu}_{1}: Q_{1}^{*}$ values of 0.110:0.00449 (run 5b, Table 1). Greyscale bar represents depth (in meter) and velocity vector scale as shown

with effects of geostrophic adjustment within the outflowing bottom layer (Pratt et al. 2000). However, these also appear to be accentuated by the topographic constriction associated with the up-sloping, converging channel approach to the FBC sill, imposing retroflection and recirculation in the dense water overflow layer. This mechanism, in turn, appears to have a strong regulatory influence on the outflow flux through the FBC. Evidence of similar cyclonic and anti-cyclonic eddies have been inferred previously through observational evidence gathered during field surveys in the region (Hansen and Østerhus 2000; Sherwin et al. 2006). The current studies also demonstrate that observed flow intrusions and separations
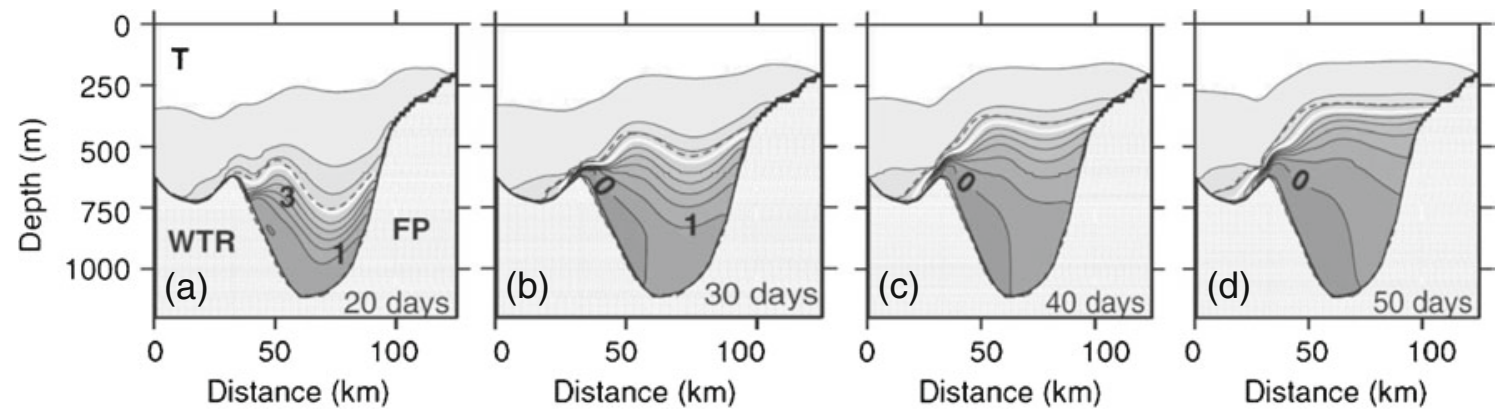

Fig. 14 Full-scale MITgcm simulations of the thermocline development at the WTB transect (dotted white line; Fig. 2) after 20, 30, 40 and 50 days (taken from Stashchuk et al. 2011). Temperature contours shown are in degree Celsius 
associated with these circulations can lead to different dense water outflow pathways through the WTB [i.e. on the FP and WTR sides of the basin (see Fig. 8)]. This behaviour is in accord with the "meandering plume" description of the deepwater outflow in this region, as measured by Mauritzen et al. (2005). Indeed, the current experimental and numerical evidence suggests that these different outflow pathways through the WTB/FBC channel approach may occur at different elevations within the dense bottom layer, depending on proximity to the pycnocline.

The influence on dense water outflow pathways from any scale-induced factors arising from the vertically distorted, scaled model topography used in both current experimental and numerical studies is largely discounted by comparing results with the recent full-scale numerical model simulations of the Faroese Channels by Stashchuk et al. (2011). Good qualitative agreement is observed in the structure of the deepwater flows obtained at both scales, particularly in relation to the generation of anti-cyclonic circulation upstream of the FBC and its influence on the resulting FBC and WTR overflows. The full-scale model simulations by Stashchuk et al. (2011) also revealed a strong temporal variability in the predicted velocity fields following removal of the imposed lock at the FSC inlet boundary, as the incoming dense water fills the modelled Faroese Channel domain (see Fig. 4; Stashchuk et al. 2011). Indeed, comparing these full-scale transient model runs with corresponding simulations in the scaled, vertically distorted model domain (Fig. 13) demonstrates that the formation and evolution of the anti-cyclonic circulation at the entrance to the converging, up-sloping approach to the FBC (over the $700 \mathrm{~s}$ model run duration) is qualitatively similar to the oceanic counterpart, both showing a general migration with elapsed time towards the FBC. In this regard, both fullscale and reduced, distorted scale model runs indicate strong temporal variability in predicted outflow pathways and circulations within the WTB/FBC approach, with clear implications for (1) the regulation of volume fluxes through the FBC, (2) the variability in the WTR overflow strength and (3) the overall response of dense water outflow pathways within the Faroese Channels to parametric changes imposed at the FSC inlet boundary. However, this observed variability in the outflow pathways also makes it difficult to determine any clear parametric influences on the circulations generated within the Faroese Channels and/or the degree to which they promote WTR spillage.

In terms of the cross-channel structure of density fields observed within the WTB, it is interesting to note from the field survey by Mauritzen et al. (2005), along a similar transect to S1 (see Fig. 2), that the depth measurements of isopycnals were also observed to be strongly time-dependent, experiencing both periods of relative uplift and depression in elevation. Similarly, in full-scale MITgcm simulations of the Faroese Channels, Stashchuk et al. (2011) demonstrated an analogous structure in the isotherm elevations across the WTB [after 20 and 30 days; Fig. 14a, b] to that measured along transect $\mathrm{S} 1$ in the current scaled laboratory experiments (Fig. 9). Stashchuk et al. also noted that the isotherms evolved over time to a more fan-like structure [i.e. after 40 or 50 days; Fig. 14c, d], attributing this behaviour to the generation and evolution of the large anti-cyclonic eddy found in the WTB/FBC channel approach, which was demonstrated to form an opposing current system through the cross-section of the eddy, resulting in the observed lifting and sinking of the isotherms. The presence and evolution of a similar anti-cyclonic circulation has been demonstrated in both distorted and full scale numerical simulations, as well as in the scaled laboratory experiments and, thus, it seems likely to be the main cause of the undulating and fan-like isopycnal/isotherm structures that are both modelled and observed across the WTB. Furthermore, the observed pinching of isopycnals on the left (WTR) side of the WTB (i.e. transects S1 and S2; Fig. 9) is also in general agreement with previous field survey measurements in the Faroese Channels (e.g. Borenäs and Lundberg 1988, 2004; Mauritzen et al. 2005) and the numerical simulations of Stashchuk et al. (2011). This wedged-shaped stratification, encountered commonly in the FBC overflow, has been attributed to boundary Ekman dynamics (Johnson and Sanford 1992) and/or inviscid processes resulting from the presence of an intermediate water mass within the FBC (Borenäs et al. 2001).

Acknowledgments This work was supported by the Natural Environment Research Council (NERC) under the Strategic Ocean Funding Initiative (SOFI) programme. The authors are also grateful for the comments provided by two anonymous reviewers that have led to significant improvements in the paper.

\section{References}

Borenäs K, Lundberg P (1988) On the deep-water flow through the Faroe Bank Channel. J Geophys Res 93(C2):1281-1292

Borenäs K, Lundberg P (2004) The Faroe-Bank Channel deep-water overflow. Deep-Sea Res II 51:335-350

Borenäs K, Lake IL, Lundberg P (2001) On the intermediate water masses of the Faroe Bank Channel overflow. J Phys Oceanogr 31: 1904-1914

Cuthbertson AJS, Lundberg P, Davies PA, Laanearu J (2013) Environ Fluid Mech. doi:10.1007/s10652-013-9285-4

Cuthbertson AJS, Laanearu J, Wåhlin A, Davies PA (2011) Experimental and analytical investigation of dense gravity currents in a rotating, up-sloping and converging channel. Dynamics of Atmos Oceans 52(3):386-409

Dalziel S (2008). Digiflow users guide. http://www.damtp.cam.ac

Davies PA, Wåhlin AK, Guo Y (2006) Laboratory and analytical model studies of the Faroe Bank Channel deep-water outflow. J Phys Oceanogr 36(7):1348-1364

Ellett D (1998) Norwegian Sea Deep Water overflow across the Wyville Thomson Ridge during 1987-88. ICES Coop Res Report 225:195-205

Girton JB, Pratt LJ, Sutherland DA, Price JF (2006) Is the Faroe Bank Channel overflow hydraulically controlled? J Phys Oceanogr 36: 2340-2349 
Hansen B, Østerhus S (2000) North Atlantic-Nordic seas exchanges. Prog Oceanogr 45:109-208

Johnson GC, Sanford TB (1992) Secondary circulation in the Faroe Bank Channel overflow. J Phys Oceanogr 22:927-933

Johnson C, Sherwin TJ, Shimmield T, Smythe-Wright D (2010) Wyville Thomson Ridge overflow water: spatial and temporal distribution in the Rockall Trough. Deep Sea Res 57(10):1153-1162

Laanearu J, Davies P (2007) Hydraulic control of two-layer flow in 'quadratic'-type channels. J Hydr Res 45(1):3-12

Laanearu J, Lundberg P (2003) Topographically constrained deep-water flows in the Baltic Sea. J Hydr Res 49(4):257-265

Lake I, Borenäs K, Lundberg P (2005) Potential-vorticity characteristics of the Faroe Bank Channel Deep-Water overflow. J Phys Oceanogr 35:921-932

Marshall J, Adcroft A, Hill C, Perelman L, Heisey C (1997) A finitevolume, incompressible Navier-Stokes model for studies of the ocean on parallel computers. J Geophys Res 102:5733-5752

Mauritzen C, Price J, Sanford T, Torres D (2005) Circulation and mixing in the Faroese Channels. Deep-Sea Res I 52:883-913

Murray J (1886) The physical and biological conditions of the seas and estuaries about north Britain. Proc Phil Soc Glasgow 306-333

Olsen SM, Hansen B, Quadfasel D, Østerhus S (2008) Observed and modelled stability of overflow across the Greenland Scotland ridge. Nature 455:519-522

Orlanski I (1976) A simple boundary condition for unbounded hyperbolic flows. J Comp Phys 21(3):251-269
Pratt LJ, Helfrich K, Chassingnet EP (2000) Hydraulic adjustment to an obstacle in a rotating channel. J Fluid Mech 404:117149

Saunders P (1990) Cold outflow from the Faroe Bank Channel. J Phys Oceanogr 20:29-43

Sherwin TJ, Turrell WR (2005) Mixing and advection of a cold water cascade over the Wyville Thomson Ridge. Deep Sea Res, I 52: $1392-1413$

Sherwin TJ, Williams MO, Turrell WR, Hughes SL, Miller PI (2006) A description and analysis of mesoscale variability in the FaroeSheltand Channel. J Geophys Res 111, C03003

Sherwin TJ, Griffiths CR, Inall ME, Turrell WR (2008) Quantifying the overflow across the Wyville Thomson Ridge into the Rockall Trough. Deep Sea Res 55(4):396-404

Stashchuk N, Vlasenko V, Sherwin T (2010) Insights into the structure of the Wyville Thomson Ridge overflow current from a fine-scale numerical model. Deep-Sea Res I 57:1192-1205

Stashchuk N, Vlasenko V, Sherwin T (2011) Numerical investigation of deep water circulation in the Faroese Channels. Deep-Sea Res I 58: 787-799

van Heijst GJF, Davies PA, Davis RG (1990) Spin up in a rectangular container. Phys Fluids A2:150-159

Wåhlin AK (2002) Topographic steering of dense bottom currents with application to submarine canyons. Deep-Sea Res 49(2):305-320

Whitehead JA (1998) Topographic control of oceanic flows in deep passages and straits. Rev Geophys 36(3):423-440 